\title{
Experimental and modeling investigation of the low-temperature oxidation of $n$-heptane
}

\author{
Olivier Herbinet ${ }^{1,2}$, Benoit Husson ${ }^{1,2}$, Zeynep Serinyel ${ }^{1,2}$, Maximilien Cord ${ }^{1,2}$, Valérie \\ Warth $^{1,2}$, René Fournet ${ }^{1,2}$, Pierre-Alexandre Glaude ${ }^{1,2}$, Baptiste Sirjean ${ }^{1,2}$, Frédérique \\ Battin-Leclerc $^{1,2}$, Zhandong Wang ${ }^{3}$, Mingfeng Xie $^{3}$, Zhanjun Cheng ${ }^{3}$, and Fei Qi ${ }^{3}$ \\ 1 Université de Lorraine, Laboratoire Réactions et Génie des Procédés, UPR 3349, Nancy, \\ F-54000, France \\ ${ }^{2}$ CNRS, Laboratoire Réactions et Génie des Procédés, UPR 3349, Nancy, F-54000, France \\ ${ }^{3}$ National Synchrotron Radiation Laboratory, University of Science and Technology of China, \\ Hefei, Anhui 230029, P. R. China
}

\begin{abstract}
The low-temperature oxidation of $n$-heptane, one of the reference species for the octane rating of gasoline, was investigated using a jet-stirred reactor and two methods of analysis: gas chromatography and synchrotron vacuum ultra-violet photo-ionization mass spectrometry (SVUV-PIMS) with direct sampling through a molecular jet. The second method allowed the identification of products, such as molecules with hydroperoxy functions, which are not stable enough to be detected using gas chromatography. Mole fractions of the reactants and reaction products were measured as a function of temperature $(500-1100 \mathrm{~K})$, at a residence time of $2 \mathrm{~s}$, at a pressure of 800 torr (1.06 bar) and at stoichiometric conditions. The fuel was diluted in an inert gas (fuel inlet mole fraction of 0.005). Attention was paid to the formation of reaction products involved in the low temperature oxidation of $n$-heptane, such as olefins, cyclic ethers, aldehydes, ketones, species with two carbonyl groups (diones) and ketohydroperoxides. Diones and ketohydroperoxides are important intermediates in the low temperature oxidation of n-alkanes but their formation have rarely been reported. Significant amounts of organic acids (acetic and propanoic acids) were also observed at low temperature. The comparison of experimental data and profiles computed using an automatically generated detailed kinetic model is overall satisfactory. A route for the formation of acetic and propanoic acids was proposed. Quantum calculations were performed to refine the consumption routes of ketohydroperoxides towards diones.
\end{abstract}

\section{Keywords}

n-heptane; jet-stirred reactor; low-temperature oxidation; ketohydroperoxide; organic acids

\section{Introduction}

The oxidation of $n$-heptane has already been the subject of many experimental and modeling studies [1-32]. $n$-Heptane is one of the two primary reference fuels which are used for the octane rating for gasolines with an octane number of 0 [33]. This species is also a possible surrogate for the $n$-alkanes present in diesel fuels [34].

Corresponding author: Olivier HERBINET, Laboratoire Réactions et Génie des Procédés, Ecole Nationale Supérieure des Industries Chimiques, BP 20451, 1 rue Grandville, 54000 Nancy, France, Tel: +33 (0)3 831753 60, Fax: +33 (0)3 83178120 , 
The oxidation of $n$-heptane was previously studied in engines [1-5] and in several types of laboratory reactors such as shock tubes [6-11], rapid compression machines [12,13], jetstirred reactors [14-16], flow reactors [17], and flames [18-22]. Most of these studies were carried out under conditions of high temperature oxidation (temperature typically above 800 $\mathrm{K})$ and relatively little attention was paid to the low-temperature oxidation of $n$-heptane, especially regarding the characterization of oxygenated reaction products [12,13,15-17]. Low-temperature oxidation of hydrocarbons is of importance for the development of diesel and homogenous charge compression ignition (HCCI) engines as this particular chemistry triggers auto-ignition phenomenon [35], it is also responsible for other combustion phenomena such as cool flames and negative temperature coefficient (NTC).

The overall reaction path diagram for the low-temperature oxidation of an alkane is described in Figure 1 [35]. At low-temperature (from $500 \mathrm{~K}$ for $n$-heptane), the alkyl radicals, which are derived from the initial $n$-alkane, rather add to molecular oxygen and form peroxy-alkyl radicals (ROOO). These radicals then isomerize to hydroperoxyalkyl radicals $(\mathbf{Q O O H})$ by internal transfer of an $\mathrm{H}$-atom. $\mathbf{Q}$ QOH radicals add again to molecular oxygen (this is called the second addition) to form $\mathrm{OOQOOH}$ radicals. The OOOQOOH radicals isomerize and decompose very easily into ketohydroperoxides $(\mathrm{OQOOH})+\mathbf{O O H}$ (the $\mathrm{H}$-atom on the carbon atom bearing the hydroperoxy group can be abstracted very easily). Ketohydroperoxides, which have hydroperoxy functions with very low $\mathrm{O}-\mathrm{O}$ bond energy, decompose easily to $\mathrm{OH}$ and alkoxy radicals, allowing lowtemperature chain branching. The apparent activation energy of the sequence of reactions leading to chain branching is very low (close to $0 \mathrm{kcal} \mathrm{mol}^{-1}$ ). At intermediate temperature, $\mathbf{Q O O H}$ radicals can decompose to cyclic ethers, aldehydes or ketones $+\mathbf{Q O H}$, or to olefins $+\mathrm{HO}_{2} \boldsymbol{\bullet}$. These decomposition channels are chain carrying and have an inhibiting effect on the reaction compare to the chain branching channels. The apparent activation energy of the chain carrying reactions is larger (about $20 \mathrm{kcal} \mathrm{mol}^{-1}$ ). The inhibiting effect and the higher apparent activation energy of this intermediate temperature mechanism are responsible for the NTC phenomenon which is observed for $n$-alkanes from about $650 \mathrm{~K}$. At higher temperature, alkyl radicals rather decompose by $\beta$-scission reactions leading to small species, which react with molecular oxygen (not shown in the scheme in Figure 1). The branching is obtained from the decomposition of hydrogen peroxide $\left(\mathrm{H}_{2} \mathrm{O}_{2}\right)$ and from the reaction of $\mathrm{H}$-atoms and molecular oxygen yielding $\mathbf{O H}+\mathbf{0}$. The apparent activation energy of the high temperature mechanism is about $30 \mathrm{kcal} \mathrm{mol}^{-1}$. This explains why the reactivity increases again in the temperature region following the NTC (from $800 \mathrm{~K}$ ).

There are only few experimental studies of the low-temperature oxidation of $n$-heptane with species analysis. Dagaut et al. [16] performed an experimental study of the oxidation of $n$ heptane in a jet-stirred reactor at temperatures ranging from 550 to $1150 \mathrm{~K}$, at pressures from 1 to $40 \mathrm{~atm}$, at residence times from 0.1 to $2 \mathrm{~s}$ and under stoichiometric conditions with highly diluted mixtures in nitrogen (inlet fuel mole fraction between 0.005 and 0.01 ). The fuel mole fraction profiles exhibited a negative temperature coefficient (NTC) behavior, except at high pressure (40 atm) where it tended to disappear. The formation of many reaction products was observed during this study. Low-temperature species are mainly oxygenated species with the same skeleton as the reactant (1-heptene, 2-heptene, 3-heptene, 2-heptanone, 3-heptanone, heptanal, cis- and trans-2-methyl-5-ethyl-tetrahydrofuran, trans-2-methyl-4-propyl-oxetane, 2-propyl-tetrahydrofuran, 2-methyl-tetrahydrofuran, 2butyl-oxirane, cis-2-methyl-4-propyl-oxetane, 2,4-diethyl-oxetane, 2-ethyl-tetrahydropyran, 2-ethyl-3-propyl-oxetane, cis- and trans-2-methyl-3-butyl-oxirane) and small species such as carbon monoxide, methanol, formaldehyde, ethylene, propene. At high temperature, the formation of oxygenated species with the same skeleton as the reactant was not observed anymore and the main reaction products were unsaturated hydrocarbons (mainly olefins) and carbon oxides. 
Lenhert et al. studied the low-temperature oxidation of $n$-heptane in a pressurized flow reactor (at $8 \mathrm{~atm}$ ) [17], where a strong negative temperature coefficient (NTC) behavior was observed. Reaction products were quantified by gas chromatography. These products were carbon oxides, cyclic ethers (cis- and trans-2-methyl-5-ethyl-tetrahydrofuran, 2-propyltetrahydrofuran and 2-methyl-4-propyl-oxetane), olefins (ethylene, propene, 1-butene, 1pentene, 1-hexene, 1-heptene, cis- and trans-2-heptene and trans-3-heptene), and aldehydes (acetaldehyde, propanal, acrolein, butanal and pentanal).

Minetti et al. performed an experimental study of the oxidation of $n$-heptane in a rapid compression machine [12]. They measured ignition delay times of stoichiometric $n$-heptaneair mixtures at temperatures ranging from 600 to $900 \mathrm{~K}$ and at high pressure (3-9 bars). The obtained ignition delay time profiles versus temperature exhibit a NTC behavior. Reaction products were analyzed using gas chromatography coupled to mass spectrometry. They observed the formation of species with the same skeleton as the reactant: heptene isomers and some cyclic ethers (2-methyl,5-ethyl-tetrahydrofuran, 2-propyl-tetrahydrofuran, 2methyl,4-propyl-oxetane, and 2,4-diethyl-oxetane). Other reaction products were carbon monoxide, 1-olefins from ethylene to 1-hexene, acetaldehyde, propanal, butanal, methane, ethane and propane.

The first modeling studies about the oxidation of $n$-heptane were carried out in the late 70's and in the 80's by Coats and Williams [23] (high temperature oxidation only), and by Westbrook et al. [24,25]. In 1989, Westbrook et al. [25] proposed the first detailed kinetic model accounting for the low- and high-temperature oxidation of $n$-heptane. Since then several low- and high-temperature oxidation models were proposed for this species [26-32]. All these models were constructed using the commonly accepted low-temperature branchedchain mechanism via the formation of degenerate branching agent (hydroperoxide species) for the oxidation of hydrocarbons (Figure 1) [35]. These models were validated against experimental data available in the literature and were widely used to run engine numerical simulations (e.g., [36-38]).

The development of reliable detailed kinetic models relies on a good understanding of the reaction mechanism which occurs at low-temperature. Recently, the experimental study of the low-temperature oxidation of a small alkane, $n$-butane, was performed in a jet-stirred reactor using two methods of analysis: gas chromatography (in Nancy, France) and synchrotron vacuum ultra-violet photo-ionization mass spectrometry (SVUV-PIMS) with direct sampling through a molecular jet (in Hefei, China) [39]. Attention was paid to the identification and the quantification of reaction products such as organic acids, ketohydroperoxides $(\mathrm{OQOOH}$ species in Figure 1, which are chain branching agents responsible for the low-temperature oxidation of hydrocarbons), and products of decomposition of the ketohydroperoxides (species with two oxygenated functions such as diones). The purpose of this paper is to extend the same approach to a larger $n$-alkane: $n$ heptane. The experimental results obtained with both methods of analysis have been confronted and experimental data have been compared with simulation results computed using a detailed kinetic model generated with software EXGAS [31].

\section{Experimental method}

The oxidation of $n$-heptane was performed in a jet-stirred reactor which can be modeled as a perfectly stirred reactor. The jet-stirred reactor used in this study was designed following the rules established by the team of Professor Villermaux in the seventies [40,41]. The residence time distribution study performed by Matras and Villermaux [40] showed that a good macro-mixing was obtained. Later an annular preheating was added to the reactor to heat the reacting mixture in a very short period of time before it enters the reactor. This ensures the 
homogeneity of the temperature in the gas phase [42]. A jet-stirred reactor working at pressures up to ten bars was also developed by Dagaut et al. [43] by following the rules of Professor Villermaux [40,41]. Dagaut et al. also verified that the macro-mixing was good and that the temperature of the gas phase was homogeneous using a thermocouple [43]. Since then this reactor has often been used for numerous gas phase kinetic studies of hydrocarbons and oxygenated compounds oxidation [16,44-46].

Experiments were performed at a constant pressure of $1.06 \mathrm{bar}$, at a residence time of 2 seconds, at temperatures ranging from 500 to $1100 \mathrm{~K}$ in Nancy, and from 500 to $720 \mathrm{~K}$ in Hefei, under stoichiometric conditions. The fuel was diluted in helium in Nancy and in argon in Hefei ( $n$-heptane mole fraction of 0.005). Argon was used in Hefei because its signal (at a photo-ionization energy of $16.6 \mathrm{eV}$ ) is needed for the normalization of other signals.

The reactor, made of fused silica, consists of a quartz sphere (volume $=95 \mathrm{~cm}^{3}$ ) into which diluted reactant enters through an injection cross located at its center. The gas jets provoke high turbulence leading to homogeneity in composition and temperature of the gas phase. The reactor is operated at constant temperature and pressure and it is preceded by an annular preheating zone in which the gas temperature is increased up to the reactor temperature before entering inside. The residence time of the mixture inside the annular preheater is very short compared to its residence time inside the reactor (by a few percent). Both the spherical reactor and the annular preheating zone are heated by heating resistances rolled up around their walls in Nancy. In Hefei, because of the lateral cone, it was not possible to use heating resistances for the heating of the spherical part. A special oven with the shape of the reactor (sphere and cone) was designed and used for the heating. The reaction temperature was measured with a type $\mathrm{K}$ thermocouple inserted in the intra-annular part of the preheater (the extremity of the thermocouple is located at the center of the reactor in a glass finger in the injection cross). The accuracy of the reaction temperature with the two types of heating device was $\pm 2 \mathrm{~K}$. Gas flow rates were controlled by mass flow controllers, Coriolis flow controllers were used for n-heptane. The uncertainty in the flow measurements is around $0.5 \%$ for each controller. This results in a maximum uncertainty of about $2 \%$ in the residence time.

In France, oxygen and helium were provided by Messer and their purities are reported as 99.995 and $99.999 \%$, respectively. $n$-Heptane was provided by Sigma Aldrich (purity of 99\%). In China, gases were provided by Nanjing Special Gas Factory Co.,Ltd. Purities of argon and oxygen were $99.99 \%$ and $99.999 \%$ respectively. $n$-Heptane was purchased from Aladdin Reagent Co.,Ltd. with a purity of $99 \%$.

Two methods were used for the analysis of the reaction products. Online gas chromatography was used in Nancy whereas SVUV photo-ionization mass spectrometry with direct sampling through a molecular jet was used in Hefei. The first method provides the advantages of an easy separation of different isomers, a high sensitivity, and an easy and direct quantification of species but it is not suitable to analyze unstable species such as hydroperoxides as they already decompose before the analysis. The main advantage of the second method is that there is a very short delay between the sampling in the reactor and the analysis using a time of flight mass spectrometer. The separation of the different isomers is possible but requires much more treatment. The quantification of a species requires the knowledge of its photo-ionization cross section which is not available for all species (these data can only be obtained by measuring the response of known amounts of standards when they are available). 


\subsection{Analytic method used in Nancy: gas chromatography}

The outlet products were analyzed online by gas chromatography. The online analysis of products which are liquid under standard conditions was made possible by a heated transfer line between the reactor outlet and the chromatograph sampling gate which was also heated. The temperature of the transfer line can be set between ambient temperature and $473.15 \mathrm{~K}$ maximum. During the study, the temperature of the transfer line was set to $373.15 \mathrm{~K}$. This temperature was high enough to avoid condensation of species. Three gas chromatographs were used for the quantification of the different species.

The first gas chromatograph, equipped with a Carbosphere packed column, a thermal conductivity detector (TCD), and a flame ionization detector (FID), was used for the quantification of $\mathrm{O}_{2}, \mathrm{CO}, \mathrm{CO}_{2}$, methane, ethylene, acetylene, and ethane. The temperature profile was: $303.15 \mathrm{~K}$ during $10 \mathrm{~min}$ - ramp of $5 \mathrm{~K} \cdot \mathrm{min}^{-1}$ up to $573.15 \mathrm{~K}-573.15 \mathrm{~K}$ during $16 \mathrm{~min}$. The carrier gas was helium ( $25 \mathrm{~mL} \cdot \mathrm{min}^{-1}$, constant pressure, splitless). The second one was fitted with a PlotQ capillary column and a FID, and was used for the quantification of molecules from methane to reaction products containing up to 5 carbon atoms and 1 or 2 oxygen atoms maximum. The temperature profile was: $333.15 \mathrm{~K}$ during $10 \mathrm{~min}-\mathrm{ramp}$ of 5 $\mathrm{K} . \mathrm{min}^{-1}$ up to $623.15 \mathrm{~K}-623.15 \mathrm{~K}$ during $15 \mathrm{~min}$. The carrier gas was helium (2 $\mathrm{mL} \cdot \mathrm{min}^{-1}$, constant flow, split 1/10). The third one was fitted with a HP-5 capillary column and a FID and was used for the quantification of molecules which contain at least 5 carbon atoms. The temperature profile was: $313.15 \mathrm{~K}$ during $30 \mathrm{~min}$ - ramp of $5 \mathrm{~K} \cdot \mathrm{min}^{-1}$ up to $573.15 \mathrm{~K}-573.15 \mathrm{~K}$ during $8 \mathrm{~min}$. The carrier gas was helium $\left(1 \mathrm{~mL} \cdot \mathrm{min}^{-1}\right.$, constant flow, split 1/10).

Calibration was performed by injecting standards when available or by using the effective carbon number method (only applicable with the flame ionization detector) when not available. Maximum relative uncertainty in mole fractions was estimated as $\pm 10 \%$ and the limit of detection for species was about $1 \mathrm{ppm}$ for species analyzed using flame ionization detector and $100 \mathrm{ppm}$ for species analyzed using thermal conductivity detector.

The identification of reaction products was performed using a gas chromatograph equipped with a PlotQ or an HP5 capillary column and coupled to a mass spectrometer. The mass spectra of all detected reaction products were included in the NIST 08 Mass Spectra Database.

\subsection{Analytic method used in Hefei: synchrotron vacuum ultra-violet photo-ionization mass spectrometry with direct sampling through a molecular jet}

Species from the reactor were analyzed by a reflectron time-of-flight mass spectrometer (RTOF MS) with photo-ionization by synchrotron radiation. The reactor was coupled to the low pressure photo-ionization chamber through a lateral fused silica cone-like nozzle which was inserted in the spherical part. The tip of the cone was pierced by a $50 \mu \mathrm{m}$ orifice. A nickel skimmer with a $1.25 \mathrm{~mm}$ diameter aperture was located $15 \mathrm{~mm}$ downstream from the sampling nozzle. The sampled gases formed a molecular beam, which was intersected perpendicularly with synchrotron vacuum ultraviolet light. The ion signal was then detected with the RTOF MS, which was installed in the photo-ionization chamber vertically. Additional details about this experimental apparatus are available in [39].

The quantification of species is more difficult than in the case of gas chromatography; it requires the knowledge of the cross sections. This is only possible for species which are available for purchase. The relative uncertainty in the mole fractions is $\pm 25 \%$ for these species. 


\section{Experimental results}

Figures 2 to 10 display the evolution with temperature of the mole fractions of the reactants and of the reaction products. Some species quantified with both methods of analysis show a good agreement between both sets of experimental data ( $n$-heptane and oxygen in Figure 2, ethylene and propene in Figure 3, acetaldehyde in Figure 4). Experimental data obtained in Hefei allowed the measurement of the mole fraction profiles of species which were not quantified in Nancy (water in Figure 3, methanol and formaldehyde in Figure 4, ketohydroperoxides in Figure 10).

\subsection{Analyses using gas chromatography (Nancy)}

Numerous species were analyzed by online gas chromatography: $n$-heptane, oxygen and 45 reaction products. Reaction products can be classified as follows:

- Light species: carbon oxides, methane, ethane, acetylene, ethylene (Figure 3).

- 1-olefins from propene to 1-heptene (Figures 3, 6 and 7).

- Other unsaturated linear hydrocarbons: 2-heptene, 1,3-butadiene, 1,3-pentadiene, 1,4-heptadiene (Figures 6 and 7).

- Saturated and unsaturated aldehydes and ketones: acetaldehyde, acrolein, propanal, acetone, methyl-vinyl-ketone, butanal, butanone, 2-butenal, 1-penten-3-one, 2pentanone, pentanal, 2-hexanone, 1-hexen-3-one, 2-heptanone, 3-heptanone (Figures 4, 5 and 9).

- $\quad \mathrm{C}_{7}$ cyclic ethers: 2-propyl-tetrahydrofuran, 2-ethyl,5-methyl-tetrahydrofuran, 2methyl,4-propyl-oxetane, 2,4-diethyl-oxetane, 2-ethyl,3-propyl-oxirane, 2-butyl,3methyl-oxirane, and some unsaturated cyclic ethers (Figure 8).

Note that the formation of heptanal was not observed in this study whereas it was in the study by Dagaut et al. [16]. They also observed the formation of other cyclic ethers such as 2-methyl-tetrahydropyran, 2-butyl-oxirane, and 2-ethyl-tetrahydrofuran. These were not observed in this study most probably because their mole fractions were too low (under detection limit).

Some species, which have never been observed in former oxidation studies as reaction products, have been detected in the present study. These species are organic acids: acetic and propanoic acids (Figure 5), $\mathrm{C}_{7}$ species with two carbonyl functions (or diones): 2,4heptadione and 3,5-heptadione (Figure 10), dihydro-5-methyl-2(3H)-furanone, and a species which could be tetrahydro-5-methyl-2-furanmethanol (Figure 8). Note that Kurman et al. [47] also observed the formation of dihydro-5-methyl-2(3H)-furanone in the low temperature oxidation of $n$-dodecane. The formation of 3-heptene was expected [16] but this species was not observed; the corresponding peak is likely to be masked by another larger one (e.g., the peak of $n$-heptane).

Two types of mole fraction profiles were observed for these species at low-temperature (500-800 K). For some of them (e.g., carbon monoxide, 1-olefins, cyclic ethers), the mole fraction increases and decreases smoothly with the temperature with a maximum at $650 \mathrm{~K}$. For some others (e.g., organic acids, aldehydes and ketones such as propanal and acetone, and diones), the mole fraction increases abruptly with the start of the reactivity around 525 $\mathrm{K}$ with a sharp peak at $550 \mathrm{~K}$. The first type of species is known to be stable products formed in the propagation steps at low and intermediate temperatures and their mole fractions is somewhat proportional to the conversion of the reactant. Organic acids, aldehydes, ketones and diones are also stable species and the sharp peak profiles were not expected at all. The cause for this unexpected sharp peak is discussed later. 
Carbon atom balances were calculated at each studied temperature (the numbers are given in supplemental data). The relative difference in the expected and experimental numbers of carbon atoms at the outlet of the reactor is $\pm 10 \%$ except in the low-temperature region where it is $\pm 20 \%$. The larger difference in the low-temperature region is due to the non quantification of some oxygenated species.

\subsection{Analyses using SVUV photo-ionization mass spectrometry (Hefei)}

Experiments performed in Nancy were repeated in Hefei, but using SVUV photo-ionization mass spectrometry for the analysis. Figure 11 displays two mass spectra obtained at 530 and $650 \mathrm{~K}$ (photon energy of $9.5 \mathrm{eV}$ ). Mass spectra were recorded at several photon energies: $9.5,10,10.5,11,13$ and $16.6 \mathrm{eV}$. Masses were scanned from 28 to $146 \mathrm{amu}$ for photon energies of 9.5, 10, 10.5 and $11 \mathrm{eV}$, and from 15 to $146 \mathrm{amu}$ for photon energies of 13 and $16.6 \mathrm{eV}$. Figures 12 and 13 display the photo-ionization efficiency spectra of some selected masses between 56 and $146 \mathrm{amu}$. The changes in the slope in these spectra allow the identification of species according to their ionization energy (IE). Table 1 gives the photoionization energies for the species which were detected using gas chromatography. The values given in this table come from the NIST database [48].

At $530 \mathrm{~K}$, the main peaks were observed for $\mathrm{m} / \mathrm{z} 72,98,100,112,114,128$ and 146 (Figure 11). Note that species with $\mathrm{m} / \mathrm{z} 72,98,100,114$ and 128 have been observed in the gas chromatography analyses (Table 1 ), whereas no species with $\mathrm{m} / \mathrm{z} 112$ and 146 was detected. The peaks at $m / z 72,98,100,112,114,128$ are still observed in the mass spectrum obtained at $650 \mathrm{~K}$ (Figure 11). The peak at $\mathrm{m} / \mathrm{z} 146$ is not present anymore meaning that ketohydroperoxides are not detected at this higher temperature. There are new large peaks in the mass spectrum obtained at $650 \mathrm{~K}$. These peaks are at $m / z 56,70,84,85,86,99$ and 126. Note that species with $\mathrm{m} / \mathrm{z} 56,70,84,86$ were also detected in the gas chromatography analyses (Table 1), but that there was no species with $\mathrm{m} / \mathrm{z} 85,99$ and 126 . Peaks at $\mathrm{m} / \mathrm{z} 70$, 84 and 126 are likely to correspond to unsaturated species which are derived from the species with $\mathrm{m} / \mathrm{z} 72$ (butanone and butanal), $86\left(\mathrm{C}_{5} \mathrm{H}_{10} \mathrm{O}\right.$ isomers: pentanal and pentanones), and $128\left(\mathrm{C}_{7} \mathrm{H}_{12} \mathrm{O}_{2}\right.$ diones). Peaks at $\mathrm{m} / \mathrm{z} 85,99$ and 126 may correspond to fragments from larger ions.

Species assignment was performed using the photo-ionization efficiency spectra of the detected $\mathrm{m} / \mathrm{z}$ (Figures 12 and 13). Ionization energies of the possible species are indicated in the photo-ionization efficiency spectra in Figures 12 and 13. Below we discuss the species that these peaks likely correspond to.

- $\quad m / z 56:$ We were not able to find any species that certainly corresponds to this peak at as the experimental IE (about $9.2 \mathrm{eV}$ ) is lower than the IEs of the two species observed using gas chromatography for this mass: 1-butene and acrolein (IEs of 9.55 and $10.11 \mathrm{eV}$, respectively [48]). Note that this peak can also stand for isobutene and 2-butene which have lower ionization energies (IE of 9.22 and $9.11 \mathrm{eV}$, respectively [48]) but which have not been observed in the gas chromatographic analyses.

- $m / z$ 70: 2-butenal and 3-buten-2-one (IEs of 9.75 and $9.65 \mathrm{eV} \mathrm{[48])} \mathrm{or} \mathrm{it} \mathrm{could} \mathrm{also}$ correspond to 1-pentene (IE of $9.49 \mathrm{eV}$ [48]).

- $m / z$ 72: Butanal and butanone (IEs of 9.82 and $9.52 \mathrm{eV}$, respectively).

- $\quad m / z$ 84: 2-pentenal, 1-penten-3-one, and 3-penten-2-one (IEs of 9.70, 9.50 and 9.39 $\mathrm{eV}$, respectively [48]). It could also be 1-hexene (IE of $9.44 \mathrm{eV}$ [48]).

- $\quad m / z 85$ : Probably a $\mathrm{C}_{6} \mathrm{H}_{13}$ fragment coming from the decomposition of larger ions. 
- $\mathrm{m} / \mathrm{z}$ 86: Pentanal and 2-pentanone (IEs of 9.38 and $9.74 \mathrm{eV}$, respectively [48]). This peak could also correspond to 3-pentanone (IE of $9.31 \mathrm{eV}$ [48]) which was not detected by gas chromatography.

- $\quad m / z$ 98: Heptene isomers (IEs of 9.35, 8.84, and $8.77 \mathrm{eV}$ for 1-heptene, 2-heptene and 3-heptene, respectively).

- $\mathrm{m} / \mathrm{z}$ 99: Probably a $\mathrm{C}_{7} \mathrm{H}_{15}$ fragment coming from the decomposition of larger ions. This peak cannot correspond to heptyl radical isomers, which would be derived from the reactant, as their IEs (e.g. $7.90 \mathrm{eV}$ for 1-heptyl radical [48]) are much lower than the experimental value (about $8.8 \mathrm{eV}$ ) in Figure 12.

- $\quad m / z$ 100: $\mathrm{C}_{6} \mathrm{H}_{12} \mathrm{O}$ isomers (IEs of 9.72, 9.35, and $9.12 \mathrm{eV}$ for hexanal, 2-hexanone, and 3-hexanone, respectively [48]). Note that this peak does not take into account the signal for $n$-heptane at photon energies lower than $9.5 \mathrm{eV}$ (n-heptane IE is 9.93 $\mathrm{eV}[48])$.

- $\quad m / z$ 112: $\mathrm{C}_{7} \mathrm{H}_{12} \mathrm{O}$ isomers (heptenones, heptenal or cyclic ethers with one double bond) resulting from the decomposition of $\mathrm{C}_{7} \mathrm{H}_{14} \mathrm{O}$ species or it could also correspond to a fragment from a larger ion.

- $m / z$ 114: $\mathrm{C}_{7} \mathrm{H}_{14} \mathrm{O}$ isomers (species with the same skeletal as the reactant) such as heptanal, heptanone isomers and cyclic ethers. The literature [48] gives the IEs for heptanal, 2-heptanone, 3-heptanone and 4-heptanone (9.65, 9.3, 9.1, and 9.1 eV, respectively). Since there is no data for $\mathrm{C}_{7} \mathrm{H}_{14} \mathrm{O}$ cyclic ethers in the literature, zeropoint energy corrected adiabatic ionization energies have been calculated from the composite CBS-QB3 method [49] using Gaussian03 [50]. Calculated ionization energies are $9.12,9.05$, and 9.08 for $n$-propyl-tetrahydrofuran, trans-1-methyl,4ethyl-tetrahydrofuran, cis-1-methyl,4-ethyl-tetrahydrofuran, respectively (Table 2). Note that there is almost no difference in the ionization energies of the cis and the trans isomers of 1-methyl,4-ethyl-tetrahydrofuran. All these calculated and experimental ionization energies for $\mathrm{C}_{7} \mathrm{H}_{14} \mathrm{O}$ isomers are in good agreement with the experimental value for $\mathrm{m} / z 114$ (Figure 13).

- $\quad m / z$ 126: No literature data available. These species are probably unsaturated molecules deriving from the decomposition of diones (m/z 128) and of ketohydroperoxide isomers ( $\mathrm{m} / \mathrm{z} 146)$.

- $\quad m / z$ 128: Diones. As for $\mathrm{C}_{7} \mathrm{H}_{14} \mathrm{O}$ cyclic ethers, there is no data in the literature for the IEs of these species. Theoretical calculations were performed for the three most probable $\mathrm{C}_{7} \mathrm{H}_{12} \mathrm{O}_{2}$ isomers: 1,3-heptadione, 2,4-heptadione and 3,5-heptadione. These species have the two carbonyl functions separated by a $\mathrm{CH}_{2}$ group and are expected to be formed in larger amounts than other isomers because the isomerizations of ROO radicals into $\mathrm{QOOH}$ radicals through six membered ring transition states are the easiest isomerization channels [31,32]. Computed ionization energies are 9.32, 9.40 and $9.37 \mathrm{eV}$ for 1,3-heptadione, 2,4-heptadione and 3,5-heptadione, respectively (Table 2). In the photo-ionization efficiency spectra of mass 128, a change in the slope is visible at a IE of 9.3-9.4 eV, which is in agreement with the values calculated for diones.

- $m / z$ 146: Ketohydroperoxide isomers. As for diones, there is no data in the literature for these species and calculations were performed for seven different isomers (as for diones, the most probable isomers have the carbonyl and the hydroperoxide functions separated by a $\mathrm{CH}_{2}$ group). Computed ionization energies are in the range $8.87-10.65 \mathrm{eV}$ (Table 3). Note that the ionization energies of the most probable isomers (3-heptanone,5-hydroperoxyde, 1-heptanal,3-hydroperoxyde and 2-heptanone,4-hydroperoxyde) are 9.31, 9.32 and $9.57 \mathrm{eV}$, respectively. These 
computed ionization energies are in agreement with the experimental photoionization efficiency spectra of mass 146 (Figure 13).

Two other important peaks were observed at photon energies higher than $11 \mathrm{eV}$ for $\mathrm{m} / z 60$ and 74. These two correspond to acetic acid and propanoic acid respectively (IEs are 10.65 and $10.44 \mathrm{eV}$, respectively [48]). The scan in photon energy was carried out up to $10.4 \mathrm{eV}$, which is lower than the ionization of these two species and it was not possible to have a clear identification according to the ionization energies. Note that these two species were also observed in the gas chromatographic analyses (Figure 5).

\subsection{Quantification of species using SVUV photo-ionization mass spectrometry}

The experimental data obtained in Hefei were used to quantify species which were not detected using gas chromatography. Some species, which were detected with both methods (e.g., ethylene in Figure 3), have been quantified using both sets of experimental results to verify the consistency of the two sources of data. The two reactants ( $n$-heptane and oxygen) were directly calibrated by measuring the signal as a function of the mole fraction in the reactor in unreactive conditions.

The quantification of reaction products was performed using equation (1) and using the reactant signal, which was calibrated, as reference [51].

$$
x_{i}(T)=x_{r e f}(T) \times \frac{S_{i}(T)}{S_{r e f}(T)} \times \frac{\sigma_{r e f}(E)}{\sigma_{i}(E)} \times \frac{D_{r e f}}{D_{i}}
$$

$x_{i}(T)$ and $S_{i}(T)$ are the mole fraction and the signal of species i at temperature $T$, respectively. $\sigma_{I}(E)$ is the photo-ionization cross-section of species i at the photon energy $E$. $D_{i}$ is the mass discrimination factor of species i.

Ethylene was quantified using the $n$-heptane signal at $11 \mathrm{eV}$ as a reference. Cross sections used for the quantification are from Cool et al. [52] and from Zhou et al. [53], for ethylene and $n$-heptane respectively. Mole fractions calculated from the data obtained in Hefei are in very good agreement with the mole fractions obtained using gas chromatography (Figure 3). Acetaldehyde and propene were quantified using the same method, but using $n$-heptane signal at $10.5 \mathrm{eV}$ as a reference. Cross sections used for the quantification are from Person and Nicole [54] for propene and from Cool et al. [55] for acetaldehyde. Again mole fractions obtained using both methods are in very good agreement (Figures 3 and 4). Methanol and formaldehyde could not be quantified in Nancy. Their mole fractions were calculated from the $n$-heptane signal at $11 \mathrm{eV}$ (Figure 4). Cross sections used for the quantification are from Person and Nicole [56] for methanol and from Cooper et al. [57] for formaldehyde. Signals of n-heptane and of oxygen could not be used as references for the quantification of water (ionization energy of $12.621 \mathrm{eV}$ [48]) because their cross sections are not known with accuracy in this photon energy region (the cross section of oxygen varies a lot: it is $8.63 \mathrm{Mb}$ at $12.96 \mathrm{eV}, 41.36 \mathrm{Mb}$ at $12.97 \mathrm{eV}$, and $1.69 \mathrm{Mb}$ at $13.05 \mathrm{eV}$ [58]; and the cross section of $\mathrm{n}$-heptane was not measured up to $11 \mathrm{eV}$ only). The quantification was then performed using the signal of argon at the photon energy of $16.6 \mathrm{eV}$. The cross section of argon was from Samson and Stolte [59]. The mole fraction profile of water is displayed in Figure 3.

\subsection{Formation of diones and ketohydroperoxides}

It was not possible to directly quantify diones $(\mathrm{m} / \mathrm{z} 128)$ and ketohydroperoxides $(\mathrm{m} / \mathrm{z} 146)$ from the SVUV photo-ionization mass spectrometry signals as the cross sections of these species are not known (these species are not available for purchase). Therefore we compared the shape of the signals obtained using SVUV photo-ionization mass spectrometry and the shape of the mole fraction profiles obtained using gas chromatography for diones. The 
comparison in Figure 10 shows that the profiles obtained using both analytical methods are different. The signal obtained for diones using SVUV photo-ionization mass spectrometry has the shape which is usually observed for stable species with no abrupt peak when the reaction starts, whereas the mole fraction profile obtained using gas chromatography exhibits an unexpected sharp peak. Note that the peak which is visible in the mole fraction profile of diones is very similar to the profile obtained for $m / z 146$ (ketohydroperoxides) in Figure 10, which is the typical shape observed for branching agents as it was the case during the study of the oxidation of $n$-butane using SVUV photo-ionization mass spectrometry [39]. This led us to think that the sharp peak is likely due to the decomposition of ketohydroperoxides in the heated transfer line between the reactor and the gas chromatographs or in the heated injector of gas chromatographs just before the analysis. At higher temperature, ketohydroperoxides are already decomposed before they exit the reactor and the diones which are detected are only formed due to the decomposition of ketohydroperoxides in the reactor.

Thanks to these experimental observations, we can conclude that:

- The decomposition of ketohydroperoxides leads to diones and some others oxygenated species.

- The main isomers for ketohydroperoxides are those with the two groups in position 2,4 and 3,5 as we obtained mainly 2,4- and 3,5-heptadiones. This is in agreement with the low-temperature oxidation chemistry of $n$-alkanes.

- The mole fraction of ketohydroperoxides is greater than $1.3 \times 10^{-4}$ in the peak region (the value is deduced from the sum of the mole fractions of 2,4- and 3,5heptadiones).

\subsection{Formation of organic acids}

The formation of organic acids has rarely been observed in combustion experiments. Acetic acid has already been detected in the study of the oxidation of $n$-butane in a jet-stirred reactor [39] and in the study of the oxidation of $n$-butyl-cyclohexane in a flow reactor [60].

As they were not available in the literature, cross sections of acetic and propanoic acids were measured in the present work at photon energies ranging from 8.7 to $11.7 \mathrm{eV}$ using pure standards. The evolution of the cross sections of these species as a function of the photon energy is displayed in Figure 14. Note that experimental ionization energies are in very good agreement with data from the literature (10.44 and $10.65 \mathrm{eV}$ for propanoic acid and acetic acid, respectively [48]).

Mole fractions of acetic and propanoic acids were calculated from the $n$-heptane signal at 11 $\mathrm{eV}$ using the cross sections measured in this work (Figure 5). As for diones, it can be seen in Figure 5 that data obtained with both types of analyses are different: GC data exhibit a sharp peak located at $550 \mathrm{~K}$ whereas there is no sharp peak in the SVUV-PIMS data for which the maximum mole fractions are obtained around $600 \mathrm{~K}$. Again, in Nancy experiments, the higher concentration of these species results from the decomposition of ketohydroperoxides in the transfer line between the reactor and the gas chromatographs. On the other hand, the relatively lower formation of these acids in Hefei experiments can certainly be trusted as the probability of reactions in the molecular beam is very limited.

\section{Discussion}

The experimental results obtained in this study were compared with data computed using a detailed kinetic model generated using software EXGAS [30]. 


\subsection{Model description}

This model contains all types of elementary reactions which are involved in the low and high temperature oxidation chemistry of n-alkanes. It is made of three parts. The first part is a $\mathrm{C}_{0}-\mathrm{C}_{2}$ reaction base which contains the reactions of the small species having two and less than two carbon atoms. The second part is a comprehensive primary mechanism containing the reactions of the reactant and of the radicals deriving from the reactant having more than two carbon atoms (the reactions of radicals having two and less than two carbon atoms are already in the $\mathrm{C}_{0}-\mathrm{C}_{2}$ reaction base). The molecular products formed in the primary mechanism are lumped to reduce the size of the model (lumping consists in gathering the molecular products having the same global formulae and the same functional groups into one generic species). The third part is a global secondary mechanism which contains the reactions of the lumped primary products. The reactions which consume these products are written in a global way in order to promote the formation of species which are already included in the primary mechanism and in the $\mathrm{C}_{0}-\mathrm{C}_{2}$ reaction base. As an example, the lumped $\mathrm{C}_{7} \mathrm{H}_{14} \mathrm{O}_{3}$ ketohydroperoxide will decompose in one step into a $\mathrm{CO}$ molecule, an $\mathrm{OH}$ radical, a n-propyl radical and a propanal molecule [31]. The rate constant for this global reaction is the one corresponding to the breaking of the weak $\mathrm{O}-\mathrm{O}$ bond.

The initial model generated with EXGAS contained 303 species involved in 1994 reactions. Given the numerous reaction products detected during this experimental part of this work, modifications were brought to the model to better account for experimental observations:

- Lumped species have been considered individually when they were quantified in experiments. This is the case for heptene isomers, heptanones and $\mathrm{C}_{7} \mathrm{H}_{14} \mathrm{O}$ cyclic ethers.

- Reactions accounting for the formation of diones, acetic acid, propanoic acid, methyl vinyl ketone, 2-butenal, 1,3-pentadiene, 1,4-heptadiene and 2-hexanone have been added.

All these new reactions are presented in the next paragraphs.

\subsection{Modeling of the consumption of ketohydroperoxides and of the formation of diones}

In the initial model, all $\mathrm{C}_{7} \mathrm{H}_{14} \mathrm{O}_{3}$ ketohydroperoxides were lumped into one generic species and the decomposition of this species was considered in one step forming small species. Some modifications in the formation and the consumption of this species were made in order to try to reproduce the formation of intermediates which could be derived from ketohydroperoxides such as diones. As 2,4-heptadione and 3,5-heptadione were the only diones observed in the experiments, only ketohydroperoxides leading to these diones were considered individually (the ketohydroperoxide species leading to 1,3-heptadione was also considered individually, although 1,3-heptadione was not observed in the experiments). In the initial model, the lumped $\mathrm{C}_{7} \mathrm{H}_{14} \mathrm{O}_{3}$ ketohydroperoxide decomposes into small species through a global reaction and the kinetic constant was the one of the reaction of breaking of the weak O-O bond. Quantum calculations were performed in order to find other possible pathways for the consumption of ketohydroperoxides and of $\mathrm{C}_{7} \mathrm{H}_{13} \mathrm{O}_{2}$ alkoxy radicals. To reduce CPU time, these calculations were performed for $\mathrm{C}_{5} \mathrm{H}_{10} \mathrm{O}_{3}$ and $\mathrm{C}_{5} \mathrm{H}_{9} \mathrm{O}_{2}$ species using Gaussian 03 (rev. C.02) [50] and the composite CBS-QB3 method [49]. Frequency analysis has made it possible to point out one imaginary frequency for each transition state and IRC calculations confirmed that the transition state connected the reactant to the product.

One molecular route of decomposition of ketohydroperoxides to diones and water was found (reaction (2) in Figure 15). The calculated rate constant is $\mathrm{k}=1.28 \times 10^{7} \mathrm{~T}^{2.25} \exp (-44950 /$ 
RT) (units: cal, mol, $\mathrm{cm}^{3}, \mathrm{~s}$ ). Figure 16 displays the different channels that were found for the consumption of alkoxy radicals. These reactions are:

- a reaction of $\beta$-scission by breaking of a $\mathrm{C}-\mathrm{H}$ bond leading to a dione and an $\mathrm{H}$ atom (reaction (1) in Figure 16),

- a reaction of $\beta$-scission by breaking of a C-C bond leading to an aldehyde and an alkyl radical with a carbonyl group (reaction (2) in Figure 16),

- a reaction of $\beta$-scission by breaking of a $\mathrm{C}-\mathrm{C}$ bond leading to a $\mathrm{C}_{4}$ dione (ketonealdehyde) and a methyl radical (reaction (3) in Figure 16),

- a reaction of isomerization through a tree membered ring transition state (reaction (4) in Figure 16),

- a reaction of isomerization through a five membered ring transition state (reaction (5) in Figure 16).

Note that reactions (4) and (5) lead to the formation of two new radicals. In this model, we considered only reactions of oxidation with $\mathrm{O}_{2}$ for their consumption forming diones and $\mathrm{HO}_{2}$ radicals. Alkyl radicals with a carbonyl group which are obtained from the C-C $\beta$ scission reactions (reaction type (2) in Figure 16) are mainly consumed by H-atom abstractions leading to the formation of ketones such as acetone, butanone and 2-pentanone. Note that mole fractions of these three species computed with the model are slightly overpredicted (Figures 4 and 5). This is likely due to missing routes for the consumption of ketones in the secondary mechanism.

The kinetic parameters of the five reaction channels for the consumption of alkoxy radicals are given in Table 4. Note that the kinetic parameters obtained for the reactions of $\beta$-scission (1) and (2) in Figure 16 are in good agreement with the kinetic data obtained by Rauk et al. [62] (the model reactions are $\mathrm{C}_{2} \mathrm{H}_{5}-\mathrm{CH}(-\mathrm{O})-\mathrm{CH}_{3} \rightarrow \mathrm{C}_{2} \mathrm{H}_{5}-\mathrm{CO}-\mathrm{CH}_{3}+\mathrm{H}$ and $\mathrm{C}_{2} \mathrm{H}_{5}-\mathrm{CH}(-\mathrm{O}$ )$\mathrm{CH}_{3} \rightarrow \mathrm{C}_{2} \mathrm{H}_{5}+$ acetaldehyde [62]).

Another type of reaction was considered for the consumption of the $\mathrm{C}_{7} \mathrm{H}_{13} \mathrm{O}_{2}$ alkoxy radical: this is the oxidation of the radicals with molecular oxygen forming a dione and an $\mathrm{HO}_{2}$ radical. The kinetic parameters which were used are from Atkinson et al. [63] (the model reaction is i- $\mathrm{C}_{3} \mathrm{H}_{7} \mathrm{O}+\mathrm{O}_{2} \rightarrow$ acetone $+\mathrm{HO}_{2}$ and $\mathrm{k}=9.04 \times 10^{9}\left[\mathrm{~cm}^{3} \cdot \mathrm{mol}^{-1} \cdot \mathrm{s}^{-1}\right]$ $\left.\times \exp \left(-400\left[\mathrm{cal}^{\mathrm{mol}}{ }^{-1}\right] / \mathrm{RT}\right)\right)$.

Note that these new reactions have almost no effect to the global reactivity. The computed mole fraction profile of $\mathrm{C}_{7} \mathrm{H}_{14} \mathrm{O}_{3}$ ketohydroperoxides is compared with the signal at $\mathrm{m} / \mathrm{z}$ 146 obtained using SVUV photo-ionization mass spectrometry in Figure 10. There is a very good agreement between the shapes of the two profiles. Note that ketohydroperoxides decompose quasi-integrally through the breaking of the $\mathrm{O}-\mathrm{O}$ bond and that the direct elimination of water forming diones does not play a significant role.

Computed and experimental mole fractions of 2,4- and 3,5-heptadiones are displayed in Figure 10. Mole fractions are under-predicted by the model by a factor of about 40 . The kinetic analysis of the model shows that the $\mathrm{C}_{7} \mathrm{H}_{13} \mathrm{O}_{2}$ alkoxy radicals quasi exclusively react by $\beta$-scission by breaking of a C-C bond and almost not by $\beta$-scission of a $\mathrm{C}-\mathrm{H}$ bond or by oxidation with $\mathrm{O}_{2}$.

As far as diones are concerned, they mainly come from the direct elimination of water from ketohydroperoxides and from the decomposition by breaking of $\mathrm{C}-\mathrm{H}$ bond of $\mathrm{C}_{7} \mathrm{H}_{13} \mathrm{O}_{2}$ alkoxy radicals. As an example, at $650 \mathrm{~K}$, for the 3,5-heptadione, the direct elimination of 
water represents $25 \%$ of the formation of this species whereas the $\beta$-scission pathway is $75 \%$.

\title{
4.3. Modeling of the formation of acetic and propanoic acids
}

To our knowledge, no reaction pathway has yet been proposed in the literature to explain the formation of large amounts of carboxylic acids during the low-temperature oxidation of alkanes related to combustion reactions. But the formation of acids has already been investigated in atmospheric chemistry studies [64]. Besides the oxidation of olefins with ozone, an important proposed pathway is by reaction of peroxyacyl radicals with $\mathrm{HO}_{2}$ radicals [65]. Peroxyacyl radicals are obtained from adehydes by $\mathrm{H}$-abstraction followed by an addition to oxygen molecules. The following reactions have been considered in the present model:

The kinetics of reactions (3a-3c) has been experimentally and theoretically investigated by Le Crâne et al. [66]: a total rate constant of $9 \times 10^{12} \mathrm{~cm}^{3} \cdot \mathrm{mol}^{-1} \cdot \mathrm{s}^{-1}$ has been derived from this reaction at $298 \mathrm{~K}$, and it was shown that the formation of peracetic acid and oxygen was the dominant channel, followed by channel $3 \mathrm{~b}$ with a branching ratio of $20 \%$, and much less importantly by channel $3 \mathrm{c}$. Reaction $3 \mathrm{~b}$ was added to the model generated using software EXGAS [31] (reactions (1) and (2) and (3a) were already included in the generated model) with the rate constants proposed by Le Crâne et al. [66]. In reaction 3b, the formation of ozone was replaced by that of an oxygen molecule and a O-atom. The same type of mechanism was considered for the formation of propanoic acid from propanal. Figure 5 displays the comparison between computed and experimental mole fractions of acetic and propanoic acids. Computed data are in a relative good agreement with the experimental ones obtained using SVUV-PIMS.

\subsection{Modeling of other minor species}

The original EXGAS generated $n$-heptane mechanism did not contain formation routes for some experimentally observed species; methyl vinyl ketone, 2-butenal, 1,3-pentadiene, 1,4heptadiene and 2-hexanone.

Methyl vinyl ketone is assumed to be a product of metathesis reactions of higher ketones, corresponding rate constants were taken from LLNL mechanism for 2-pentanone methathesis and analogy was made for 2-hexanone and 2-heptanone metatheses. 2-butanal is assumed to be formed via higher ketohydroperoxide $(\mathrm{C} \geq 5)$ decomposition, again LLNL rate constants were assigned to these reactions.

1,3-pentadiene is assumed to be formed via hexene metathesis $\left(\mathrm{C}_{6} \mathrm{H}_{12}+\mathrm{R} \mathbf{O}=\mathrm{RH}+\mathrm{C}_{5} \mathrm{H}_{8}+\right.$ $\boldsymbol{O C H}_{3}$ ) in analogy with the metathesis of $\mathrm{C}_{5}$ olefin leading to formation of 1,3-butadiene, 
described in our mechanism. On the other hand, the $\mathrm{C}_{7}$ diene (1,4-heptadiene) is assumed to be a product of the recombination of $\mathbf{O C}_{3} \mathrm{H}_{5}$ and $\mathbf{O C}_{4} \mathrm{H}_{7}$ radicals; given the uncertainty in the rate constant of this combination reaction, collision limit $\left(1 \times 10^{14} \mathrm{~cm}^{3} \cdot \mathrm{mol}^{-1} \cdot \mathrm{s}^{-1}\right)$ was assigned for this reaction, resulting in a slight over-prediction at temperatures above $800 \mathrm{~K}$.

2-hexanone is assumed to be produced via beta scission from $\mathrm{C}_{6} \mathrm{H}_{12} \mathrm{OOH}$, a rate constant of $1.90 \times 10^{9} \exp \left(-7500 / \mathrm{RT}\right.$ ) (units cal, mol, $\mathrm{cm}^{3}$, s) was assigned in analogy with the beta scission of $\mathrm{C}_{5} \mathrm{H}_{10} \mathrm{OOH}$ forming 2-pentanone.

In addition to these, an acetone sub-mechanism was adopted as described in Pichon et al. [67].

\subsection{Comparison of experimental and computed data}

Mole fractions computed with the model were compared with experimental data (Figures 2 to 9). Simulations were also performed using the model developed by LLNL [61], the overall agreement is similar to that obtained with EXGAS model. The comparison is available in supplemental data. Figure 2 displays the comparison of computed and experimental data for the reactants ( $n$-heptane and oxygen). The model reproduces well the reactivity over the whole range of temperatures. The agreement is also very good for small species such as carbon oxides, methane, acetylene, ethylene and water (Figure 3). The formation of ethane is slightly over-estimated in the high temperature region whereas the opposite trend is observed for propene (Figure 3).

As far as $\mathrm{C}_{1}-\mathrm{C}_{6}$ oxygenated species are concerned (Figures 4 and 5), the agreement is satisfactory for acetaldehyde, butanal and pentanal. It deteriorates slightly for methanol, formaldehyde, acrolein, propanal, and 2-pentanone. According to the kinetic analysis of our model, the over-prediction of formaldehyde is not due to lumped reactions as this species is only formed from reactions included in the $\mathrm{C}_{0}-\mathrm{C}_{2}$ reaction base. Note that mole fractions of these species are also over-predicted by the LLNL model. For propanal and acrolein, the over prediction of the mole fractions is due to the rules of decomposition of species which were used in the model to simplify the secondary mechanism. Note that 1-penten-3-one and 1-hexen-3-one are not included in the model.

For $\mathrm{C}_{4}-\mathrm{C}_{7}$ hydrocarbons (Figures 6 and 7), the agreement is satisfactory for 1-butene, 1,3butadiene, 1-pentene, 1,3-pentadiene, 1-hexene and 1,4-heptadiene. As far as heptene isomers are concerned, only comparisons for 1- and 2-heptenes were possible as 3-heptene was not detected in experiments. Computed mole fractions of 1-heptene are under-predicted whereas the opposite trend is observed for 2-heptene. Note that mole fractions computed with the LLNL model are in a correct agreement for 1-heptene but over-predicted for 2heptene.

The comparison of computed and experimental mole fractions of $\mathrm{C}_{7} \mathrm{H}_{14} \mathrm{O}$ cyclic ethers is displayed in Figure 8. The comparison is only displayed for cyclic ethers observed in experiments (2-propyl-tetrahydrofuran, 2-ethyl,5-methyl-tetrahydrofuran, 2-methyl,4propyl-oxetane, 2,4-diethyl-oxetane, 2-ethyl,3-propyl-oxirane, 2-butyl,3-methyl-oxirane). The agreement is overall satisfactorily for four and five membered ring cyclic ethers. The model over-predicts the formation of three membered ring cyclic ethers. Note that the formation of three and four membered ring cyclic ethers at high temperature predicted by the model is not observed in the experiments (whereas it is in the case of five membered ring cyclic ethers). This is likely due to mole fractions being below the detection limit ( 10-20 $\mathrm{ppm}$ ). Comparison is not given for dihydro-5-methyl-2(3h)-furanone and 2-furanmethanol, tetrahydro-5-methyl as routes of formation and consumption are not included in the model. 
The comparison for 2- and 3-heptanone is displayed in Figure 9 (4-heptanone was not detected in experiments). Note that heptanones were initially represented in a lumped species, these were de-lumped into 2-, 3- and 4-heptanones. The computed mole fractions are significantly over-predicted by the model. This is mostly due to the large uncertainty in activation energy resulting from the $\mathrm{C}_{7} \mathrm{H}_{15} \mathrm{OO}=\mathbf{O C}_{7} \mathrm{H}_{14} \mathrm{OOH}$ isomerization rate constants. Figure 9 also shows the comparison for all $\mathrm{C}_{7} \mathrm{H}_{14} \mathrm{O}$ isomers (heptanal, heptanones and cyclic ethers). Computed mole fractions are under-estimated by a factor of 2 .

\subsection{Kinetic analysis of the model}

Flux analyses at $650 \mathrm{~K}$ and $850 \mathrm{~K}$ are represented in Figures 17 and 18. $n$-Heptane mainly decomposes into 2- and 3-heptyl radicals via $\mathrm{H}$-atom abstractions $(71.4 \%$ at $650 \mathrm{~K}$ and 64.6 $\%$ at $850 \mathrm{~K})$. On the other hand, 1- and 4-heptyl radicals are produced to a lesser extent $(28.6 \%$ at $650 \mathrm{~K}$ and $34.1 \%$ at $850 \mathrm{~K})$. Decomposition pathways of the most abundant fuel radicals are shown in Figures 17 and 18. As is typical in low temperature alkane chemistry (Figure 17), the fuel radical adds to molecular oxygen and goes through $\mathrm{ROO}=\mathbf{Q Q O O H}$ isomerization type, which eventually results in the formation of $\mathrm{C}_{7}$ ketohydroperoxides and $\mathrm{C}_{7} \mathrm{H}_{14} \mathrm{O}$ species (heptanal, heptanones and cyclic ethers, as shown. At higher temperature (850K, see Figure 18), heptyl radicals mainly decompose into smaller species through reactions of $\beta$-scission. Note that reactions of oxidation (to heptenes plus $\mathrm{HO}_{2}-$ ) and of addition to $\mathrm{O}_{2}$ still play a role at this temperature.

\section{Conclusion}

The experimental study of the oxidation of $n$-heptane was performed in a jet-stirred reactor and reaction products were analyzed using two complementary methods: gas chromatography and SVUV photo-ionization mass spectrometry. A model for the low and high temperature oxidation of $n$-heptane was generated using software EXGAS. The comparison of experimental and computed data is satisfactorily, keeping in mind that most discrepancies in the mole fractions of intermediates at low temperature are due to some globalization in the secondary mechanism to limit the size of the model.

Important intermediates in the low temperature oxidation of hydrocarbons were detected in this study. The formation of ketohydroperoxides was observed using SVUV-PIMS, confirming the previous identification of this type of species in the low temperature oxidation of $n$-butane. The computed profile matched well the experimental mole fraction profile.

The formation of species with two carbonyl groups was also observed using both analytical techniques. Gas chromatography analyses allowed the separation of two isomers: 2,4- and 3,5-heptadiones. The gas chromatography mole fraction profiles of these two species were unusual because of the presence of a sharp peak at the lowest temperatures (as for ketohydroperoxides). This was likely due to the decomposition of ketohydroperoxides during their transfer in the line between the reactor and the gas chromatographs. New reaction pathways were added in the model in order to account for the formation of these species from the ketohydroperoxides, however the result was not successful as the computed mole fractions are still under-predicted by a factor 40 .

The presence of organic acids, acetic and propanoic acids, was observed. The two sets of experimental data obtained with both analytical techniques show differences. As for diones, these species are likely to be formed from the decomposition of ketohydroperoxides in the heated transfer line between the reactor and the gas chromatograph. A route of formation of acetic acid from acetaldehyde was included in the present model. 
This study shows that the chemistry of the low temperature of hydrocarbons is responsible for the formation of many species with low individual concentrations and that the current scheme of the low temperature oxidation of hydrocarbons which is included in the current models still needs to be refined to better account for the formation of minor pollutants observed in the experiments. Experimental studies of model molecules smaller than $n$ heptane along with quantum calculations and modeling studies are still necessary for a better understanding of the low temperature oxidation chemistry of hydrocarbons.

\section{Supplementary Material}

Refer to Web version on PubMed Central for supplementary material.

\section{Acknowledgments}

This study was supported by the European Commission through the "Clean ICE" Advanced Research Grant of the European Research Council.

This work was granted access to the HPC resources of CINES under the allocation 2011086686 made by GENCI (Grand Equipement National de Calcul Intensif).

\section{References}

1. Kim DS, Lee CS. Fuel. 2006; 85(5-6):695-704.

2. Tanaka S, Ayala F, Keck JC, Heywood JB. Combust. Flame. 2003; 132(1-2):219-239.

3. Lu XC, Chen W, Huang Z. Fuel. 2005; 84(9):1074-1083.

4. Lu XC, Chen W, Huang Z. Fuel. 2005; 84(9):1084-1092.

5. Szybist JP, Boehman AL, Haworth DC, Koga H. Combust. Flame. 2007; 149(1-2):112-128.

6. Fieweger K, Blumenthal R, Adomeit G. Combust. Flame. 1997; 109(4):599-619.

7. Gauthier BM, Davidson DF, Hanson RK. Combust. Flame. 2004; 139(4):300-311.

8. Herzler J, Jerig L, Roth P. Proc. Combust. Inst. 2005; 30(1):1147-1153.

9. Vasu SS, Davidson DF, Hanson RK. Combust. Flame. 2009; 156(4):736-749.

10. Akih-Kumgeh B, Bergthorson JM. Energy Fuels. 2010; 24(4):2439-2448.

11. Davidson DF, Hong Z, Pilla GL, Farooq A, Cook RD, Hanson RK. Combust. Flame. 2010; 157(10):1899-1905.

12. Minetti R, Carlier M, Ribaucour M, Therssen E, Sochet LR. Combust. Flame. 1995; 102(3):298309.

13. Silke EJ, Curran HJ, Simmie JM. Proc. Combust. Inst. 2005; 30(2):2639-2647.

14. Chakir A, Bellimam M, Boettner JC, Cathonnet M. Int. J. Chem. Kinet. 1992; 24(4):385-410.

15. Dagaut P, Reuillon M, Cathonnet M. Combust. Sci. Technol. 1994; 95:233-260.

16. Dagaut P, Reuillon M, Cathonnet M. Combust. Flame. 1995; 101(1-2):132-140.

17. Lenhert DB, Miller DL, Cernansky NP, Owens KG. Combust. Flame. 2009; 156:549-564.

18. Berta P, Aggarwal SK, Puri IK. Combust. Flame. 2006; 145(4):740-764.

19. Holley AT, Dong Y, Andac MG, Egolfopoulos FN. Combust. Flame. 2006; 144(3):448-460.

20. Liu W, Zhu D, Wu N, Law CK. Combust. Flame. 2010; 157(2):259-266.

21. Yao C, Cheng C, Liu S, Tian Z, Wang J. Fuel. 2009; 88(9):1752-1757.

22. Smallbone AJ, Liu W, Law CK, You XQ, Wang H. Proc. Combust. Inst. 2009; 32(1):1245-1252.

23. Coats CM, Williams A. Symposium (International) on Combustion. 1979; 17(1):611-621.

24. Westbrook CK, Dryer FL. Prog. Energy Combust. 1984; 10(1):1-57.

25. Westbrook CK, Warnatz J, Pitz WJ. Symposium (International) on Combustion. 1989; 22(1):893901.

26. Ranzi E, Gaffuri P, Faravelli T, Dagaut P. Combust. Flame. 1995; 103(1-2):91-106.

27. Lindstedt RP, Maurice LQ. Comb. Sci. Tech. 1996; 120(1-6):119-167. 
28. Come GM, Warth V, Glaude PA, Fournet R, Battin-Leclerc F, Scacchi G. Symposium (International) on Combustion. 1996; 36:755-762.

29. Curran HJ, Gaffuri P, Pitz WJ, Westbrook CK. Combust. Flame. 1998; 114(1-2):149-177.

30. Buda F, Bounaceur R, Warth V, Glaude PA, Fournet R, Battin-Leclerc F. Combust. Flame. 2005; 142(1-2):170-186.

31. Biet J, Hakka MH, Warth V, Glaude PA, Battin-Leclerc F. Energy Fuels. 2008; 22(4):2258-2269.

32. Westbrook CK, Pitz WJ, Herbinet O, Curran HJ, Silke EJ. Combust. Flame. 2009; 156(1):181199.

33. Pitz WJ, Cernansky NP, Dryer FL, Egolfopoulos FN, Farrell JT, Friend DG, Pitsch H. SAE paper. 2007; 01:0175.

34. Farrell JT, Cernansky NP, Dryer FL, Friend DG, Hergart CA, Law CK, McDavid RM, Mueller CJ, Patel AK, Pitsch H. SAE paper. 2007; 01:0201.

35. Walker, RW.; Morley, C. "Basic Chemistry of Combustion" in Comprehensive Chemical Kinetics: Gas Phase Combustion. Pilling, MJ., editor. Elsevier; Amsterdam: 1997. p. 35

36. Curran HJ, Gaffuri P, Pitz WJ, Westbrook CK, Leppard WR. Symposium (International) on Combustion. 1996; 26(2):2669-2677.

37. Bounaceur R, Glaude PA, Fournet R, Battin-Leclerc F, Jay S, Pires Da Cruz A. Int. J. Vehicle Des. 2007; 44(1-2):124-142.

38. Guo H, Neill WS, Chippior W, Li H, Taylor JD. J. Eng. Gas Turb. Power. 2010; 132(2):1-10.

39. Herbinet O, Battin-Leclerc F, Bax S, Le Gall H, Glaude PA, Fournet R, Zhou Z, Deng L, Guo H, Xieb M, Qi F. Phys. Chem. Chem. Phys. 2011; 13(1):296-308. [PubMed: 21031192]

40. Matras D, Villermaux J. Chem. Eng. Sci. 1973; 28:129-137.

41. David R, Matras D. Can. J. Chem. Eng. 1975; 53:297.

42. Chambon M, Marquaire PM, Côme GM. C1 Mol. Chem. 1987; 2:47-59.

43. Dagaut P, Cathonnet M, Rouan JP, Foulatier R, Quilgars A, Boettner JC, Gaillard F, James H. J. Phys. E : Sci. Instrum. 1986; 19:207-209.

44. Battin-Leclerc F, Herbinet O, Glaude PA, Fournet R, Zhou Z, Deng L, Guo H, Xie M, Qi F. Angew. Chem. Int. Edit. 2010; 49(18):3169-3172.

45. Dagaut P, Togbé C. Fuel. 2010; 89(2):280-286.

46. Glaude PA, Herbinet O, Bax S, Biet J, Warth V, Battin-Leclerc F. Combust. Flame. 2010; 13(1): 296-308.

47. Kurman MS, Natelson RH, Cernansky NP, Miller DL. Proc. Combust. Inst. 2011; 33(1):159-166.

48. NIST Chemistry Webbook NIST Standard Reference Database 69 NIST. Gaithersburg; MD: 2005. http://webbook.nist.gov/chemistry/

49. Montgomery JA, Frisch MJ, Ochterski JW, Petersson GA. J. Chem. Phys. 1999; 110:2822-2827.

50. Frisch, MJ., et al. Gaussian03, revision B05 Gaussian, Inc. Wallingford; CT: 2004.

51. Zhang LD, Cai JG, Zhang TC, Qi F. Combust. Flame. 2010; 157(9):1686-1697.

52. Cool TA, Wang J, Nakajima K, Taatjes CA, McIlroy A. Int. J. Mass Spectrom. 2005; 247:18-27.

53. Zhou Z, Zhang L, Xie M, Wang Z, Chen D, Qi F. Rapid Commun. Mass Spectrom. 2010; 24(9): 1335-1342. [PubMed: 20391606]

54. Person JC, Nicole PP. J. Chem. Phys. 1970; 53(5):1767-1774.

55. Cool TA, Nakajima K, Mostefaoui TA, Qi F, McIlroy A, Westmoreland PR, Law ME, Poisson L, Peterka DS, Ahmed M. J. Chem. Phys. 8356; 2003(16):8365.

56. Person JC, Nicole PP. J. Chem. Phys. 1971; 55(7):3390-3397.

57. Cooper G, Anderson JE, Brion CE. Chem. Phys. 1996; 209:61-77.

58. Fennelly JA, Torr DG. Atom Data Nucl. Data Tables. 1992; 51(2):321-363.

59. Samson JAR, Stolte WC. J. Electron Spectrosc. Relat. Phenom. 2002; 123(2-3):265-276.

60. Natelson RH, Kurman MS, Cernanski NP, Miller DL. Combust. Flame. 2011; 158(12):2325-2337.

61. Mehl M, Pitz WJ, Westbrook CK, Curran HJ. Proc. Combust. Inst. 2011; 33(1):193-200.

62. Rauk A, Boyd RJ, Boyd SL, Henry DJ, Radom L. Can. J. Chem. 2003; 81:431-442. 
63. Atkinson R, Baulch DL, Cox RA, Hampson RF, Kerr JA, Troe J. J. Phys. Ref. Data. 1989; 18(3): 881-1097.

64. Chebbi A, Carlier P. Atmospheric Environment. 1996; 30:4233-4249.

65. Calvert, JG.; Mellouki, A.; Orlando, JJ.; Pilling, MJ.; Wallington, TJ. The mechanisms of atmospheric oxidation of the oxygenates. Oxford Univ. Press; 2011.

66. Le Crâne JP, Rayez MT, Rayez JC, Villenave E. Phys. Chem. Chem. Phys. 2006; 8:2163-2171. [PubMed: 16751874]

67. Pichon S, Black G, Chaumeix N, Yahyaoui M, Curran HJ, Simmie JM, Donohue R. Combust. Flame. 2010; 157(1):363-373. 


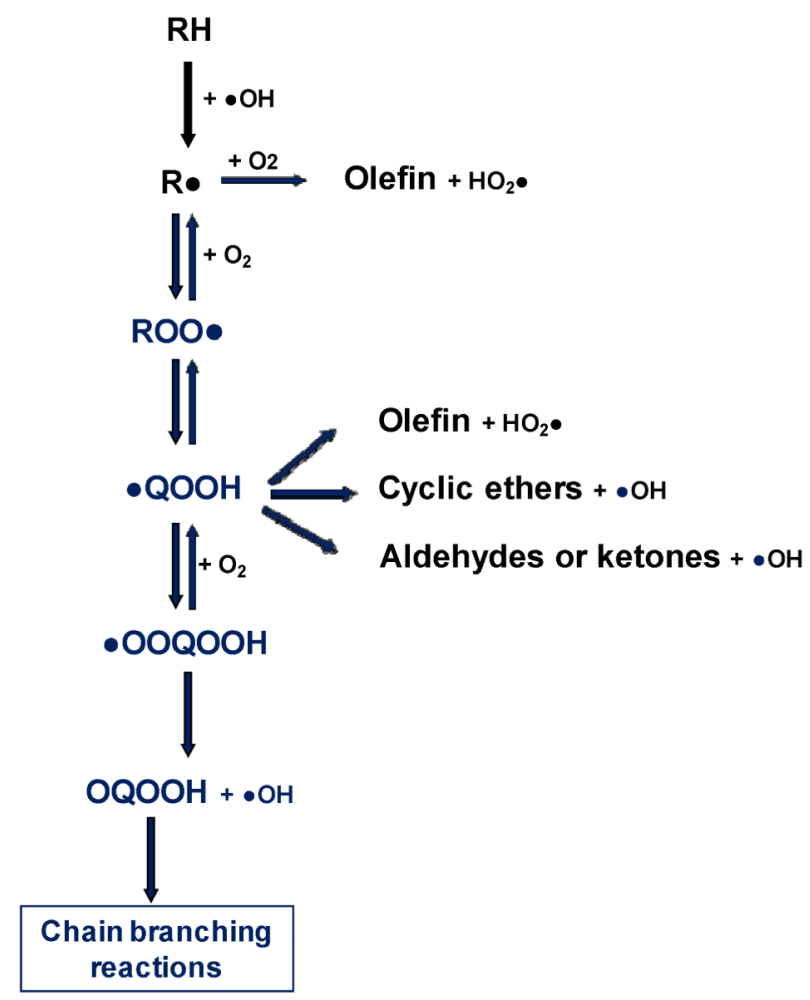

Figure 1.

Overall reaction path diagram of the low-temperature oxidation of an alkane $(\mathrm{RH})$. 

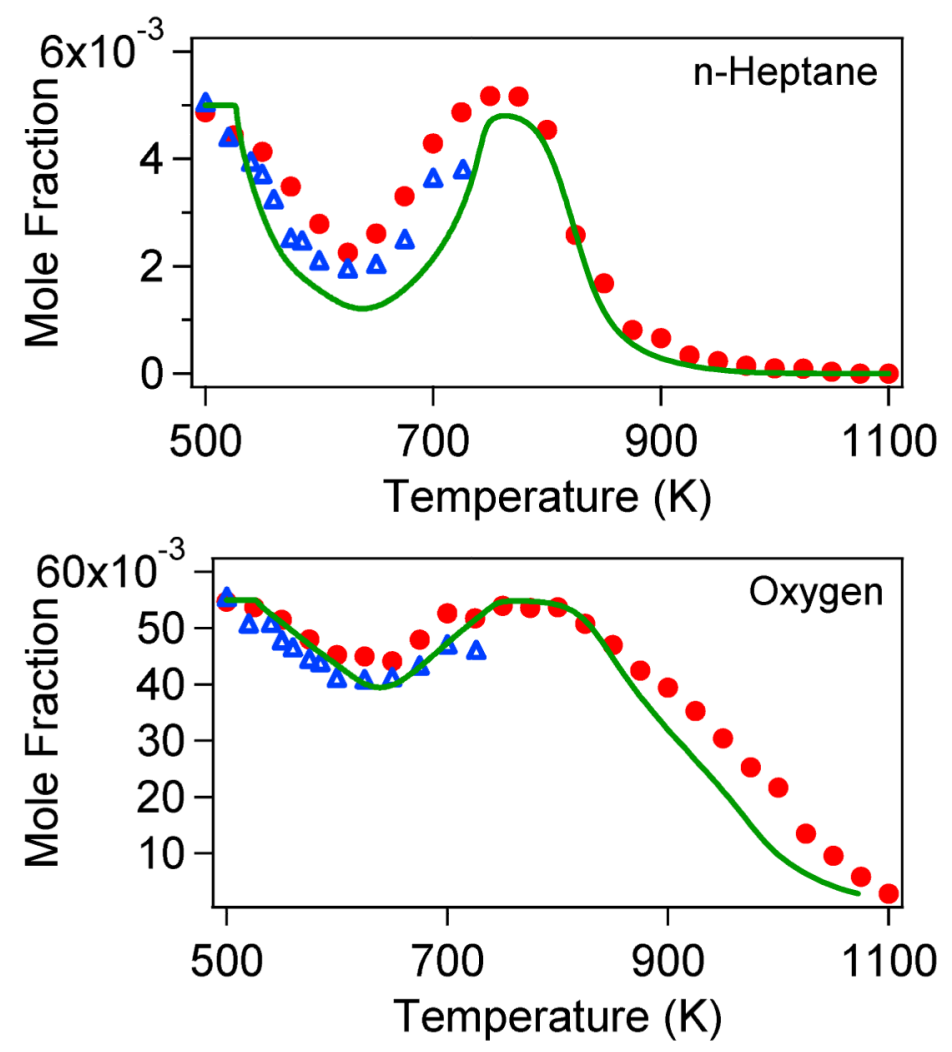

Figure 2.

Mole fractions of the reactants. O: Experimental results obtained in Nancy. $\Delta$ : Experimental data obtained in Hefei (the signals of $n$-heptane and oxygen obtained at 10.5 and $13 \mathrm{eV}$, respectively, were calibrated using the experimental data obtained in Nancy). — : Simulation. 

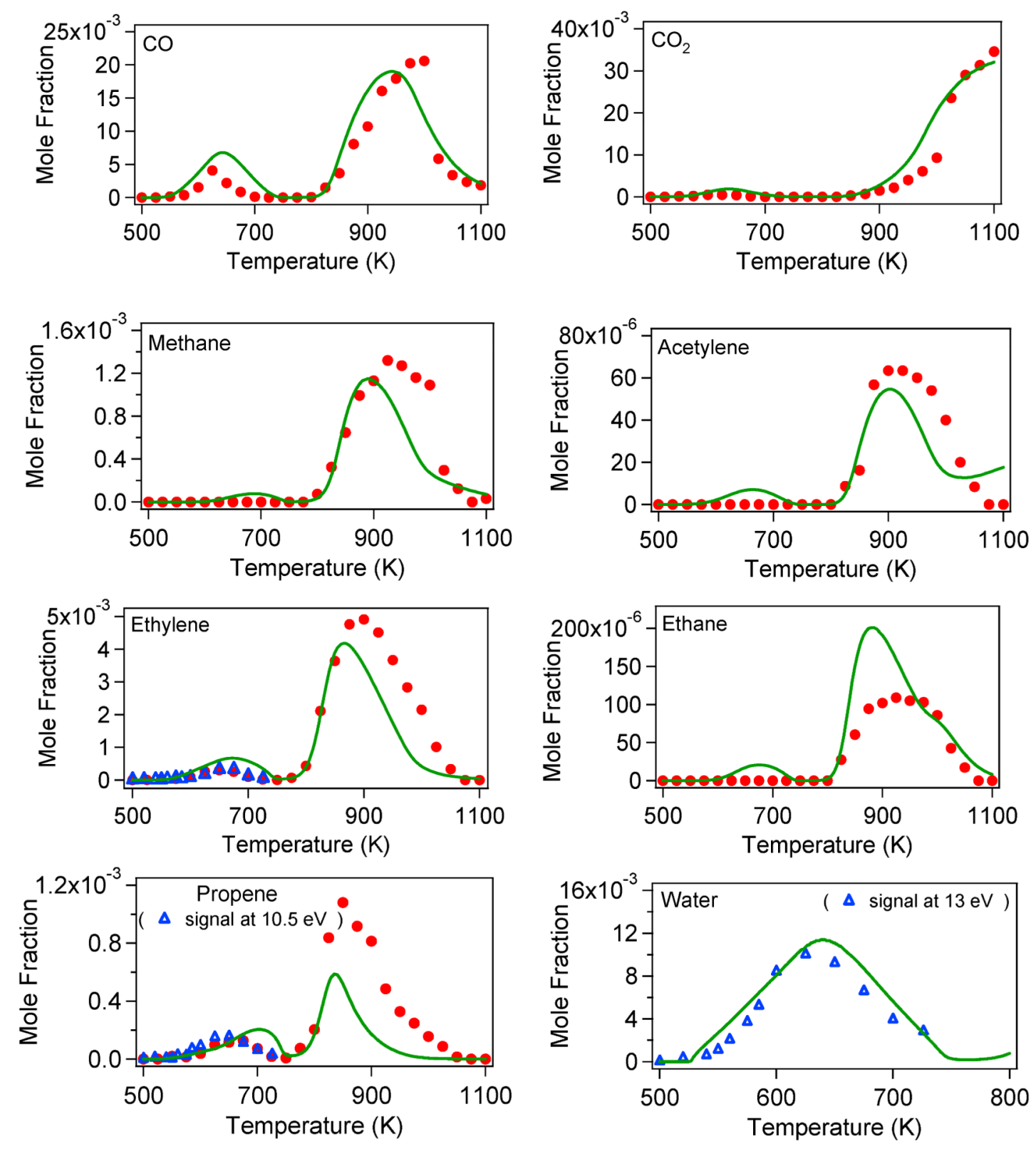

Figure 3.

Mole fractions of carbon oxides, $\mathrm{C}_{1}-\mathrm{C}_{3}$ hydrocarbons and water. 0 : Experimental results obtained in Nancy. $\Delta$ : Experimental data obtained in Hefei (mole fractions of propene, ethylene and water were calculated from the signals obtained at 10.5, 11 and $13 \mathrm{eV}$, respectively). —: Simulation. 

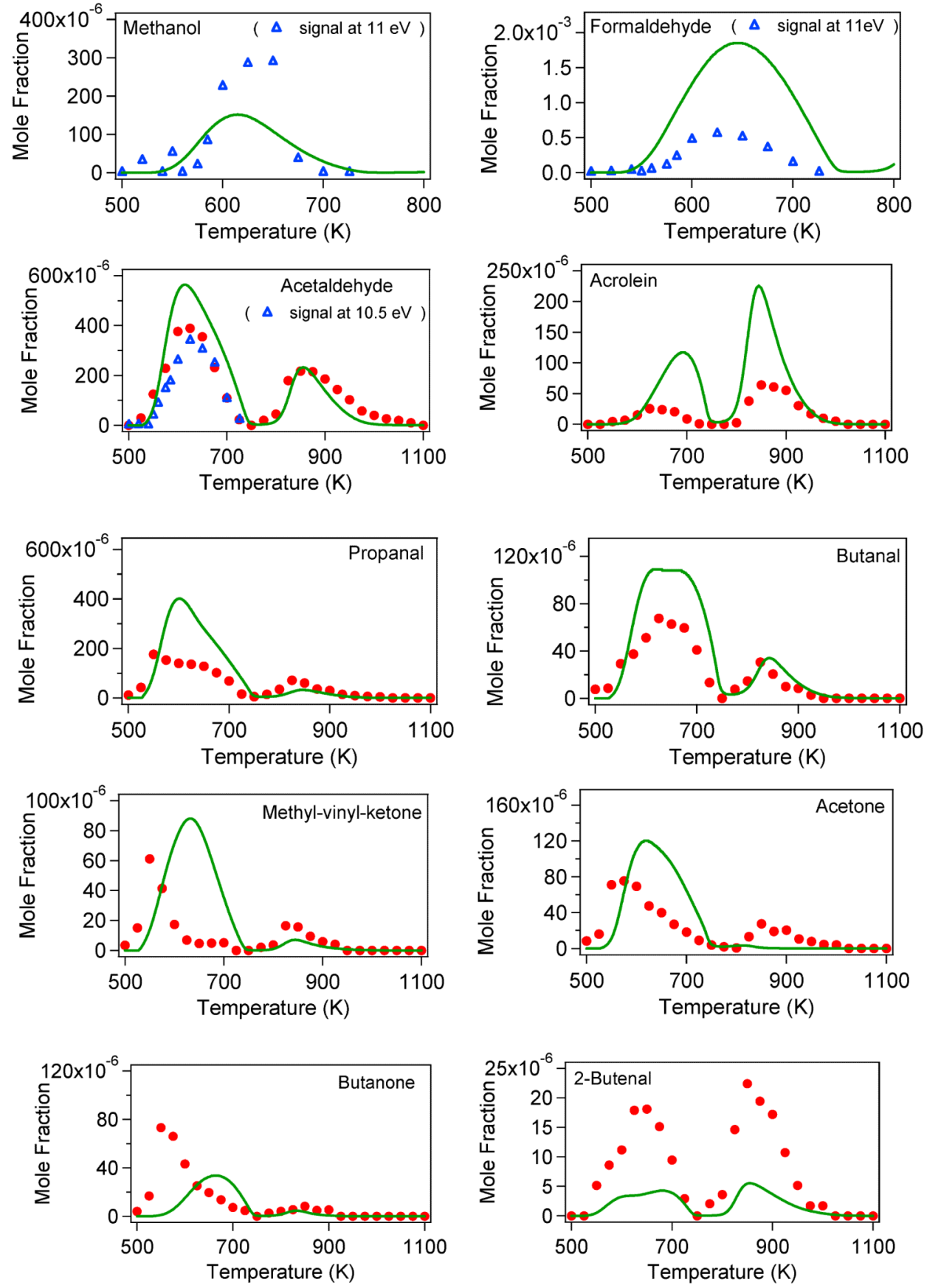

Figure 4.

Mole fractions of $\mathrm{C}_{1}-\mathrm{C}_{6}$ oxygenated products (Part I). @: Experimental results obtained in Nancy. $\Delta$ : Experimental data obtained in Hefei (mole fractions of methanol and formaldehyde were calculated from the signals obtained at $11 \mathrm{eV}$ and the one of acetaldehyde from the signal obtained at $10.5 \mathrm{eV}$ ). —: Simulation. 

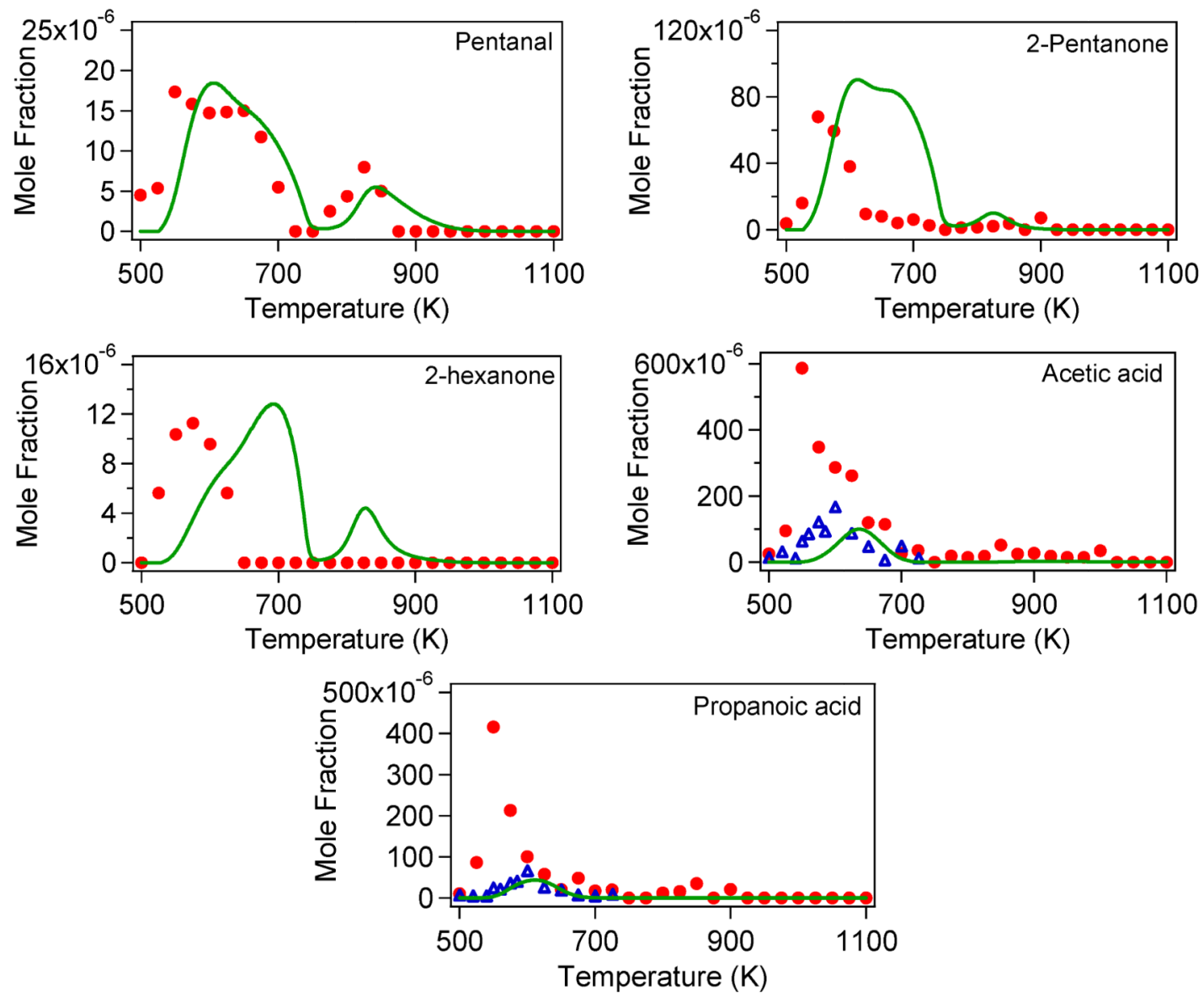

Figure 5.

Mole fractions of $\mathrm{C}_{1}-\mathrm{C}_{6}$ oxygenated products (Part II). $\mathrm{O}$ : Experimental results obtained in Nancy. $\Delta$ : Experimental data obtained in Hefei (mole fractions of organic acids were calculated from the SVUV-PIMS signals obtained for $\mathrm{m} / \mathrm{z} 60$ and 74 at $11 \mathrm{eV}$ ). Simulation. 

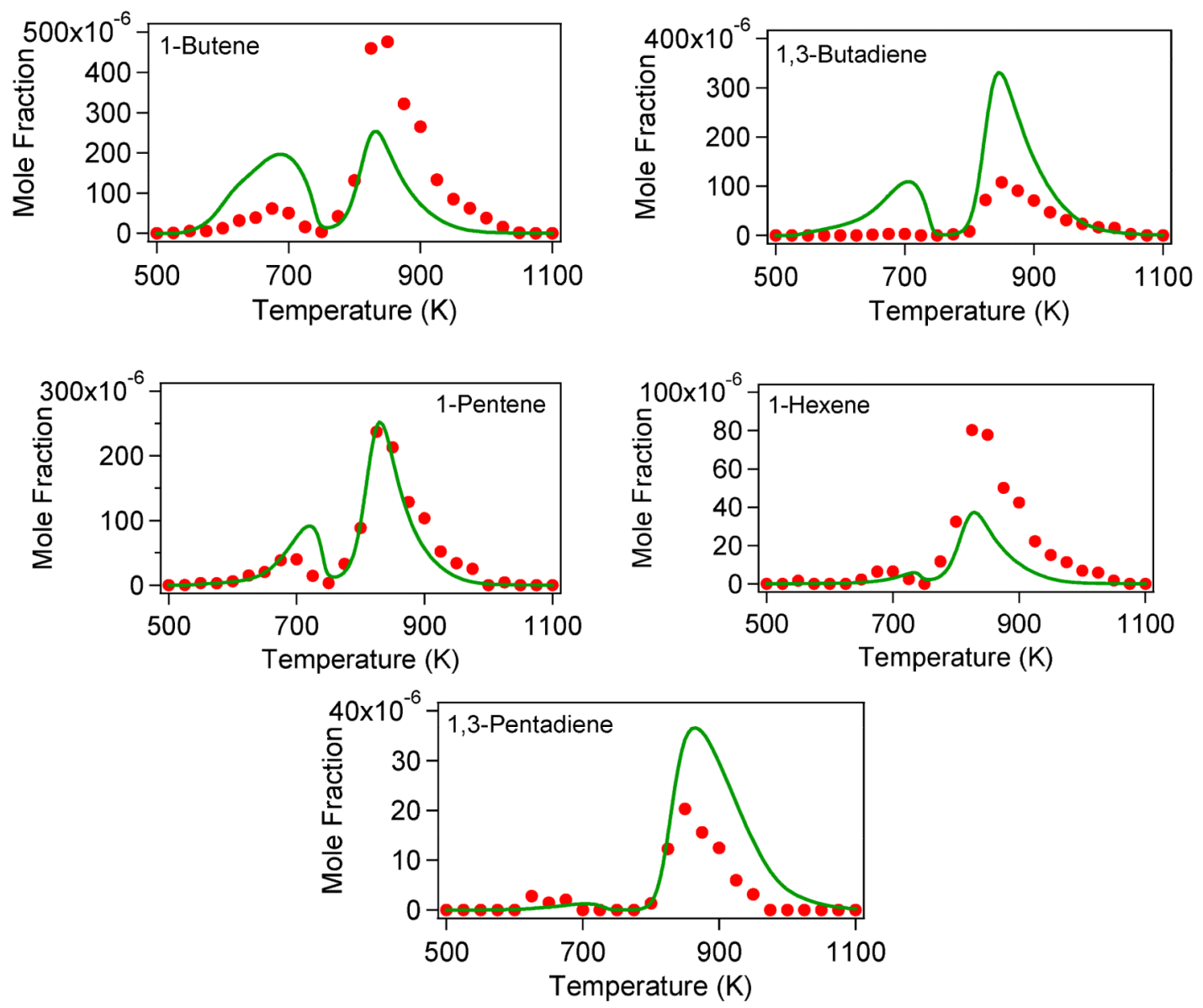

Figure 6.

Mole fractions of $\mathrm{C}_{4}-\mathrm{C}_{6}$ unsaturated hydrocarbons. $\mathrm{O}$ : Experimental results obtained in Nancy. - : Simulation. 

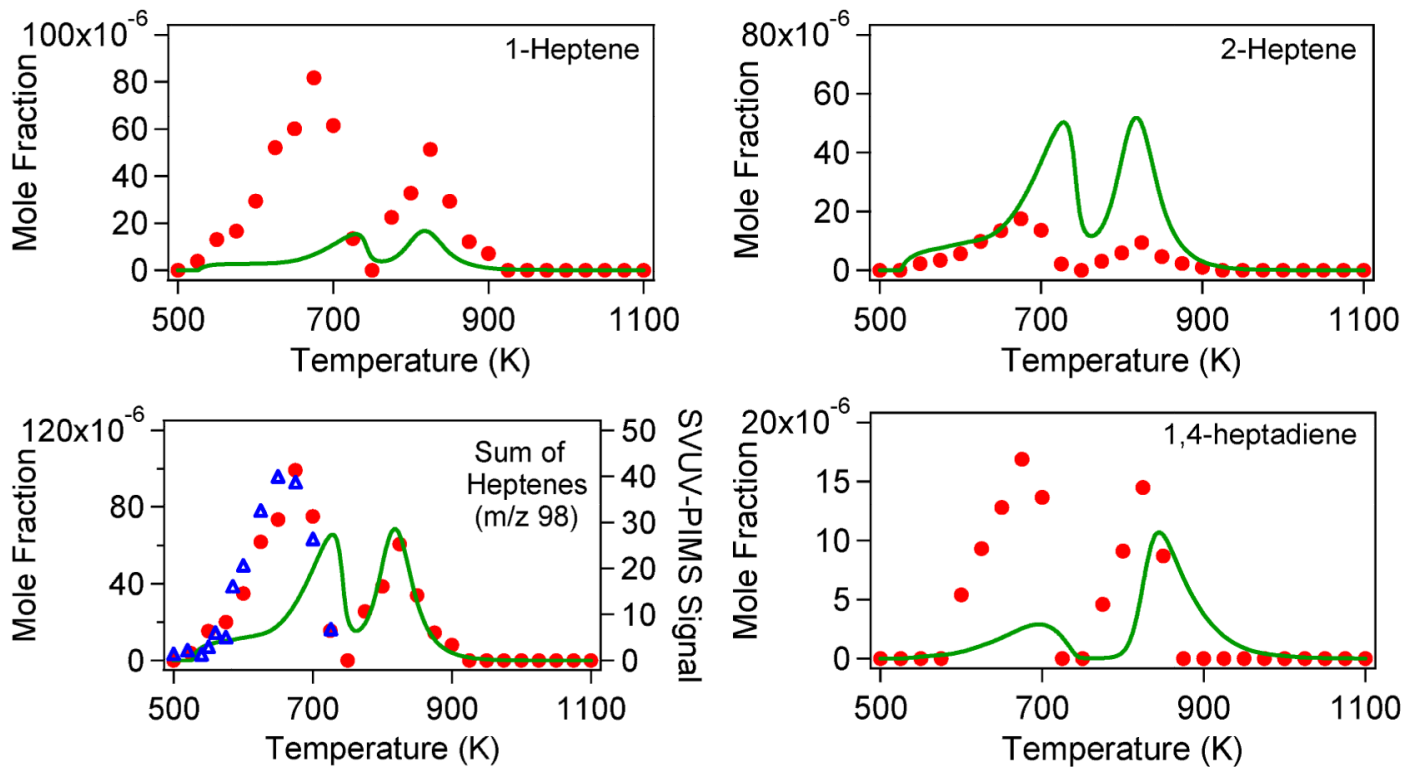

Figure 7.

Mole fractions of $\mathrm{C}_{7}$ unsaturated hydrocarbons. : Experimental results obtained in Nancy. $\Delta$ : Experimental data obtained in Hefei (the signal for $\mathrm{m} / \mathrm{z} 98$ was obtained at $10 \mathrm{eV}$ ). —: Simulation. 

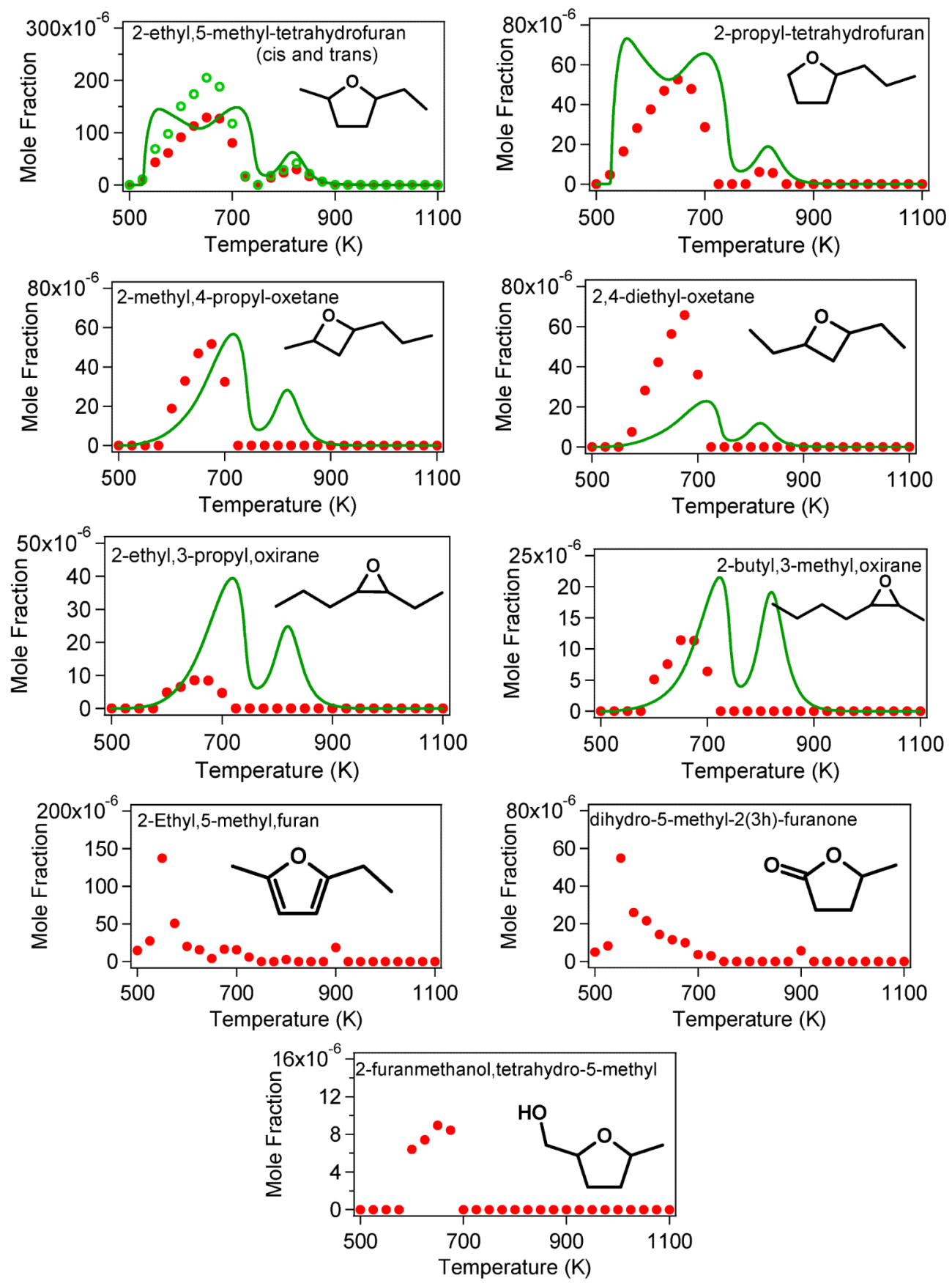

Figure 8.

Mole fractions of $\mathrm{C}_{7}$ cyclic ethers. $\mathrm{O}$ and $\bigcirc$ : Experimental results obtained in Nancy. —: Simulation. 

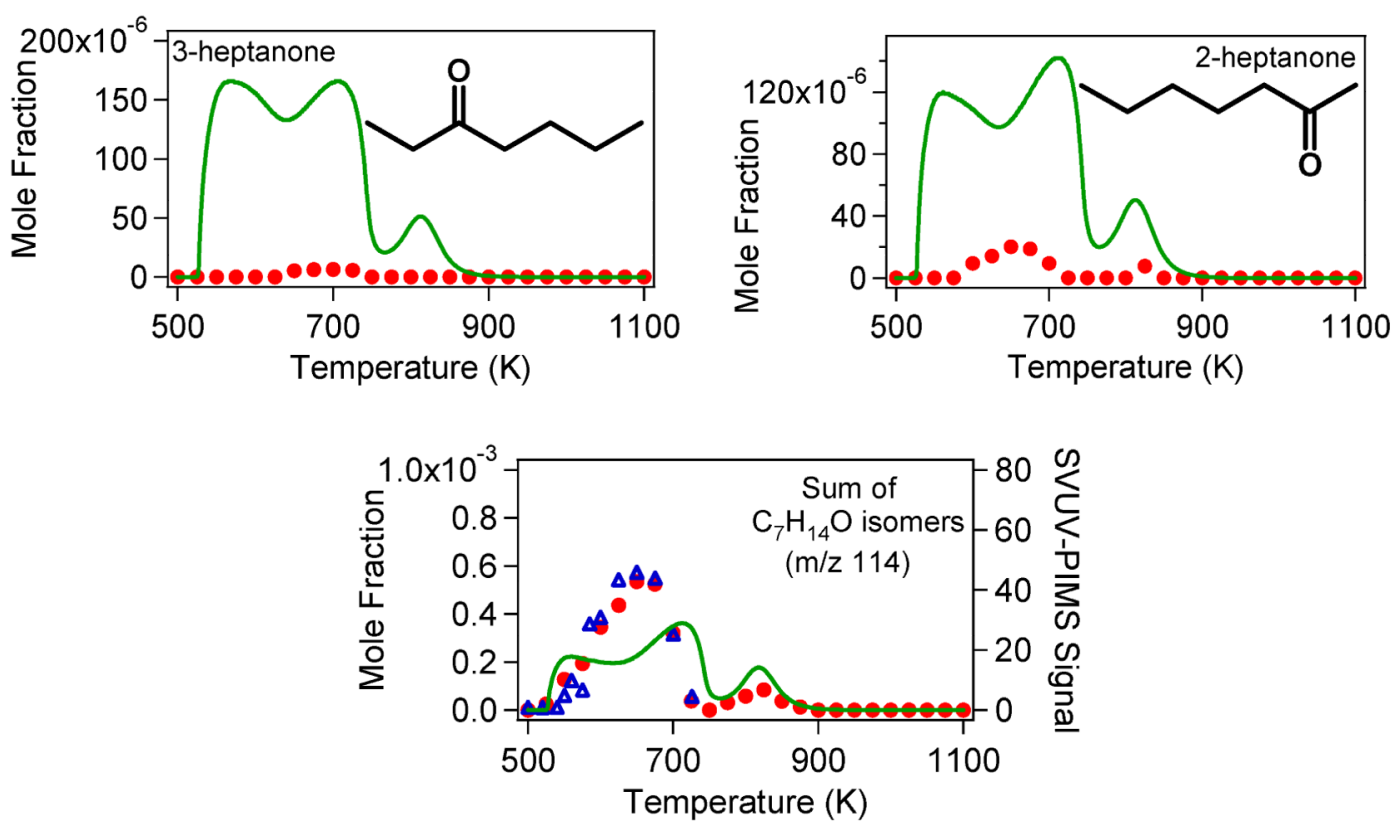

Figure 9.

Mole fractions of $\mathrm{C} 7$ species with one oxygen atom. Experimental results obtained in Nancy. $\Delta$ : Experimental data obtained in Hefei (the signal for $m / z 114$ was obtained at 10 eV). -:Simulation. 

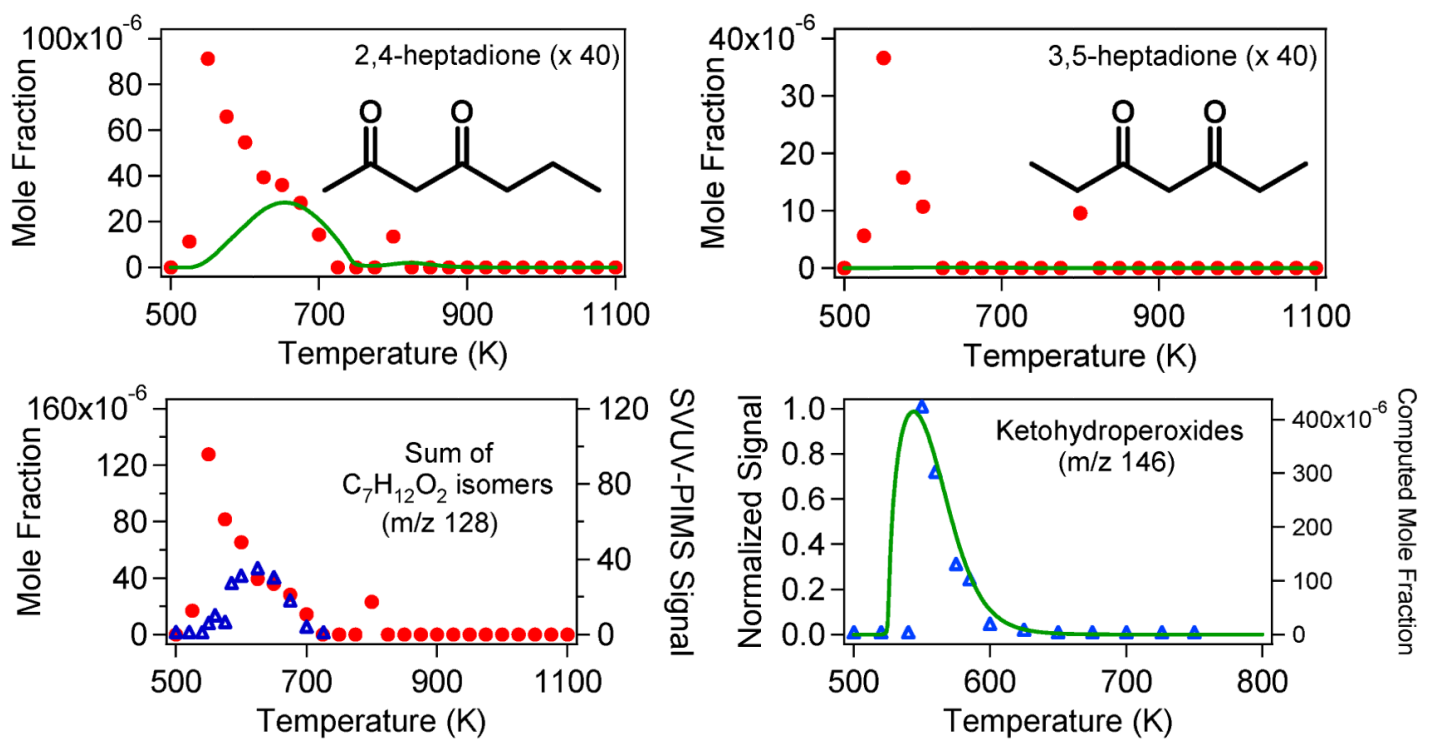

Figure 10.

Mole fractions of $\mathrm{C}_{7}$ species with two or three oxygen atoms. $\mathrm{O}$ : Experimental results obtained in Nancy. $\Delta$ : Experimental data obtained in Hefei (the signal for $\mathrm{m} / z 128$ and $\mathrm{m} / \mathrm{z}$ 146 were obtained at 10 and $9.5 \mathrm{eV}$, respectively). - : Simulation. 

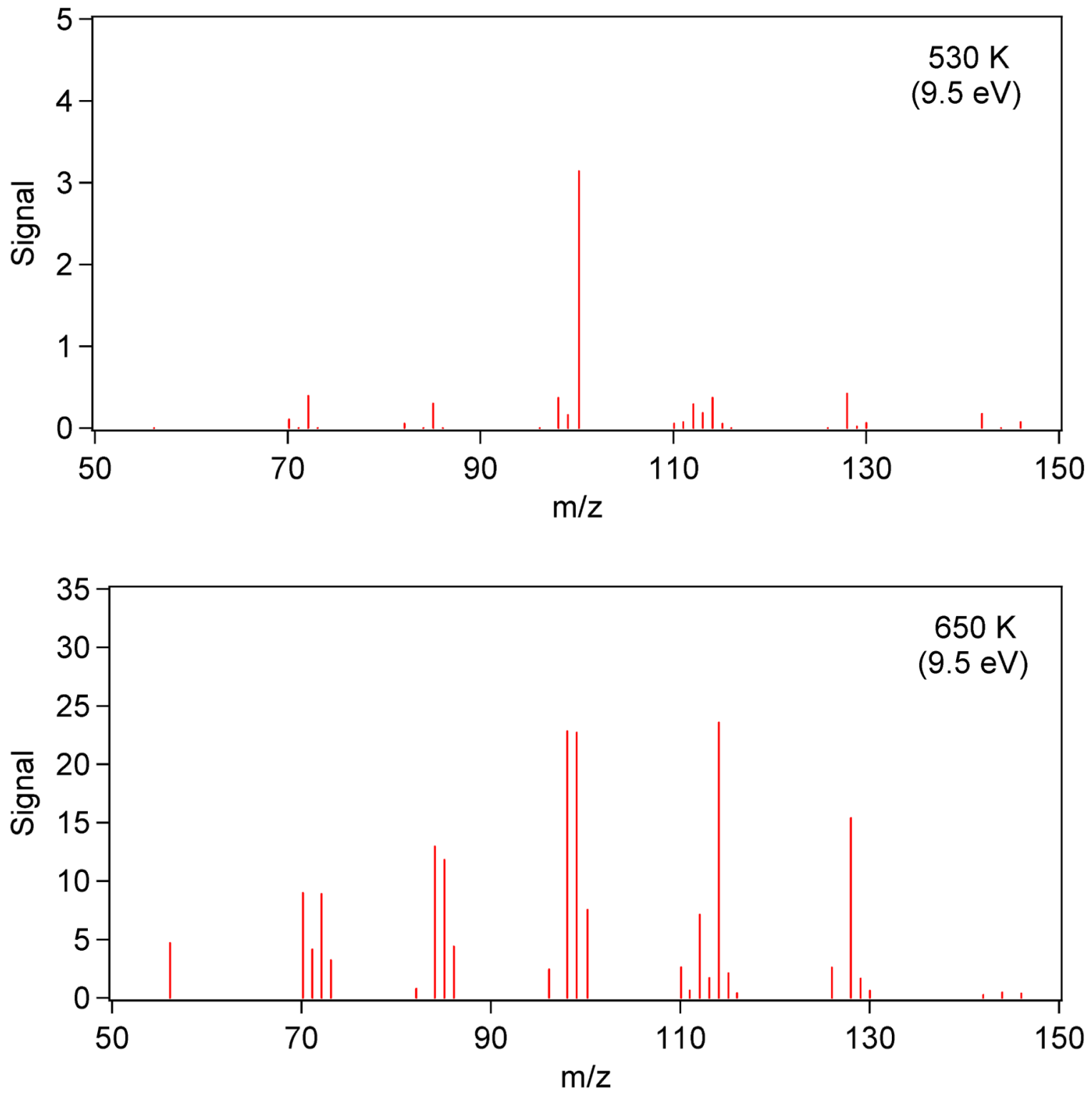

Figure 11.

Mass spectra obtained during experiments performed at $530 \mathrm{~K}$ and $650 \mathrm{~K}$ and with a photon energy of $9.5 \mathrm{eV}$. 



Figure 12.

Photo-ionization efficiency spectra of mass $56,70,72,84,85,86,98$, and 99 sampled from the reactor. The temperature in the reactor was $600 \mathrm{~K}$. 

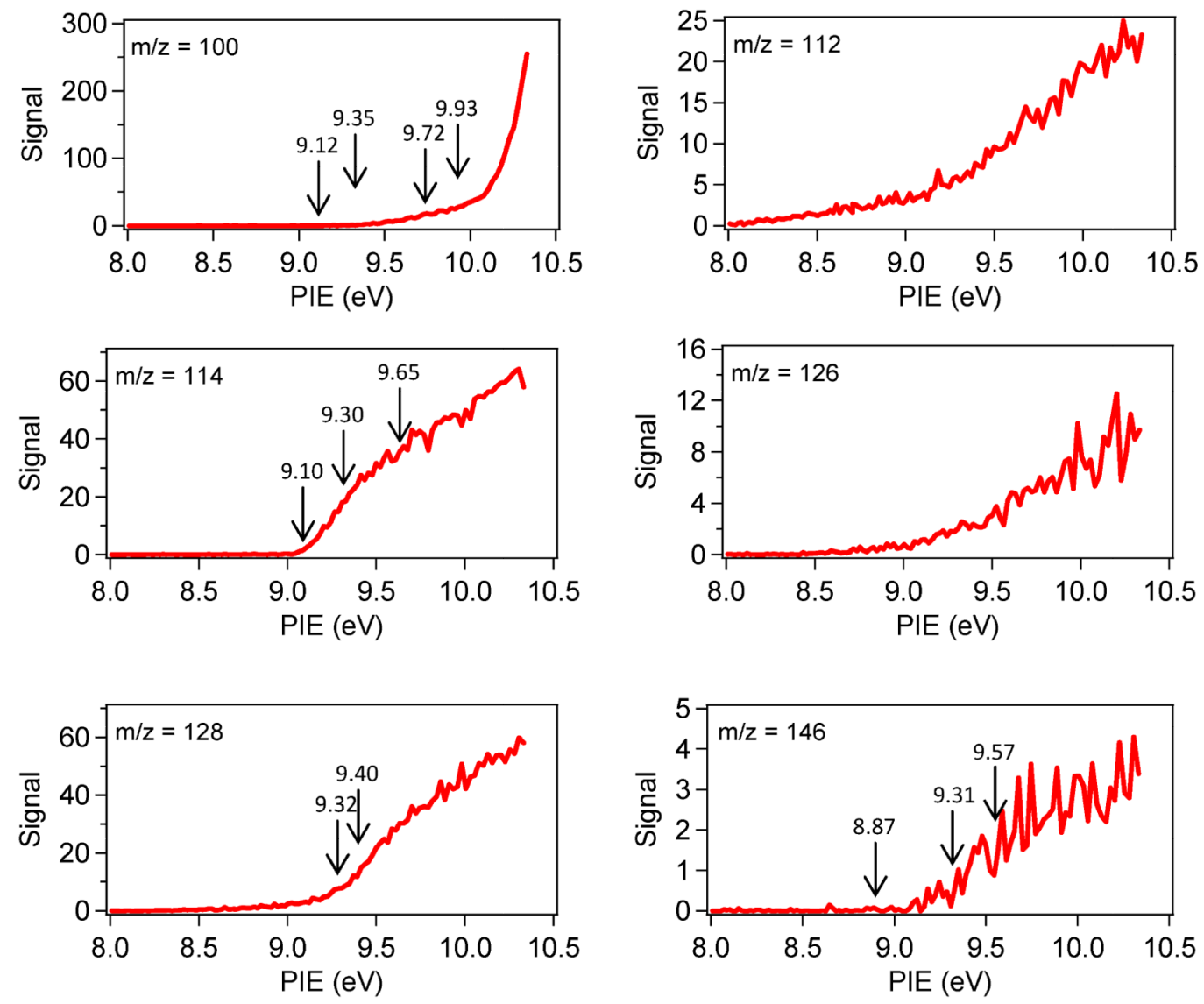

Figure 13.

Photo-ionization efficiency spectra of mass 100, 112, 114, 126, 128, and 146 sampled from the reactor. The temperature in the reactor was $600 \mathrm{~K}$. 


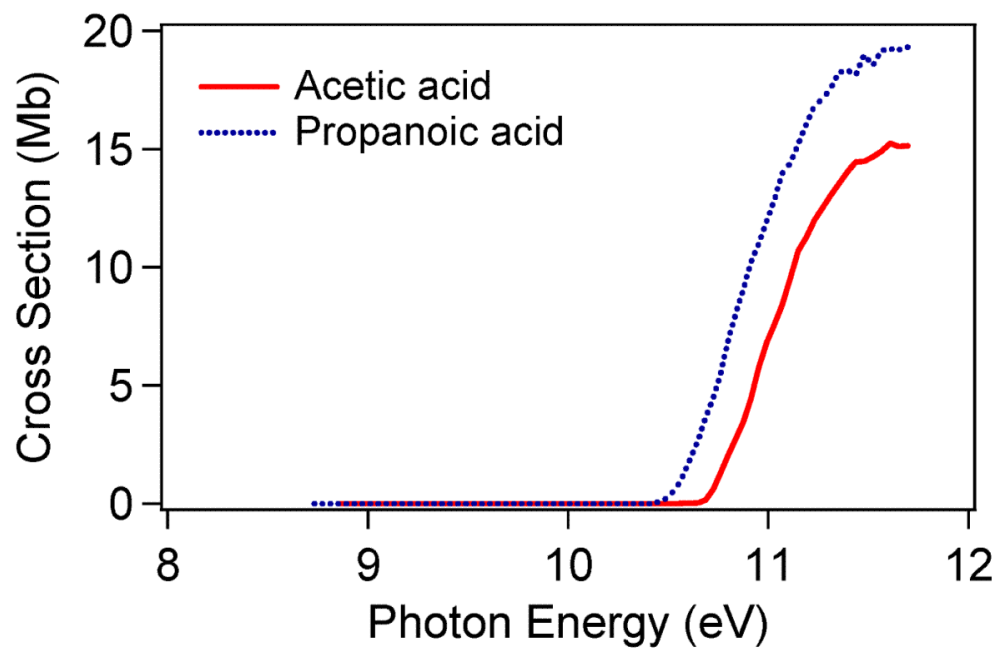

Figure 14.

Evolution of the cross sections of acetic and propanoic acids as a function of the photon energy (this work). 


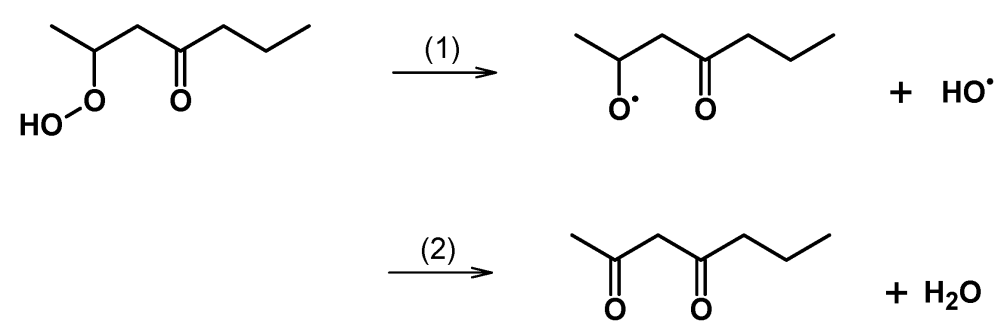

Figure 15.

Reactions which were considered for the decomposition of ketohydroperoxide species. 
<smiles>CC(=O)CC(C)=O</smiles><smiles>C#CC</smiles><smiles>CC(=O)CC(C)[O]</smiles><smiles>CC(C)=O</smiles><smiles>CC(=O)C(C)C(C)O</smiles><smiles>[CH]1[CH]CCC1</smiles><smiles>C1CCCC1</smiles><smiles>CC(=O)CC=O</smiles>
$+\mathrm{CH}_{3}^{\circ}$

(4)<smiles>C[C](O)CC(C)=O</smiles>

Figure 16.

Possible reactions for a model $\mathrm{C}_{5} \mathrm{H}_{9} \mathrm{O}_{2}$ alkoxy radical. The reaction pathways were found from quantum calculations and were used to describe the fate of the $\mathrm{C}_{7} \mathrm{H}_{13} \mathrm{O}_{2}$ alkoxy radicals involved in the model of the oxidation of $n$-heptane. 


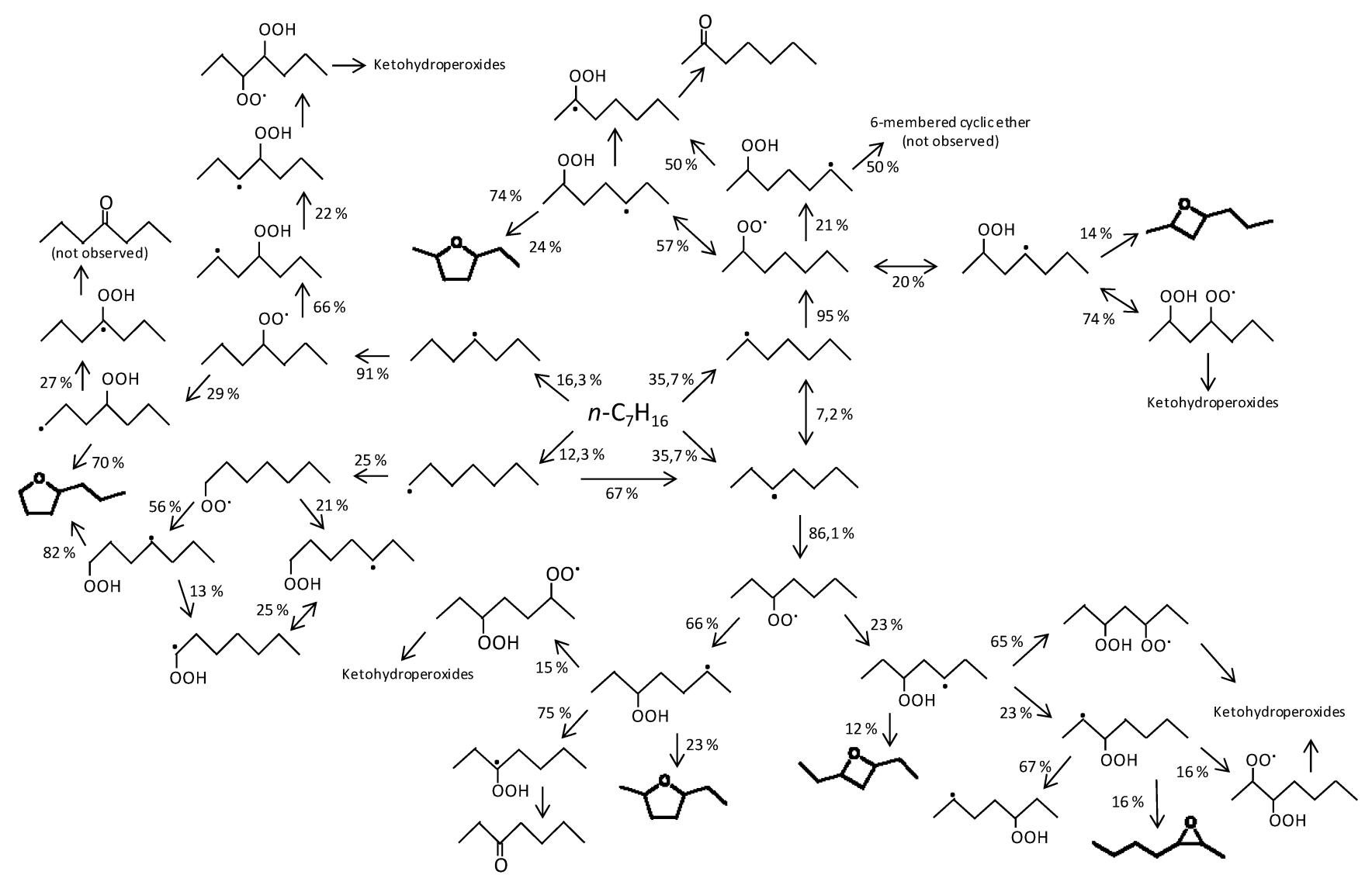

Figure 17.

Rate of production analysis performed at low temperature $(650 \mathrm{~K})$ using the $n$-heptane oxidation model developed in this study. 


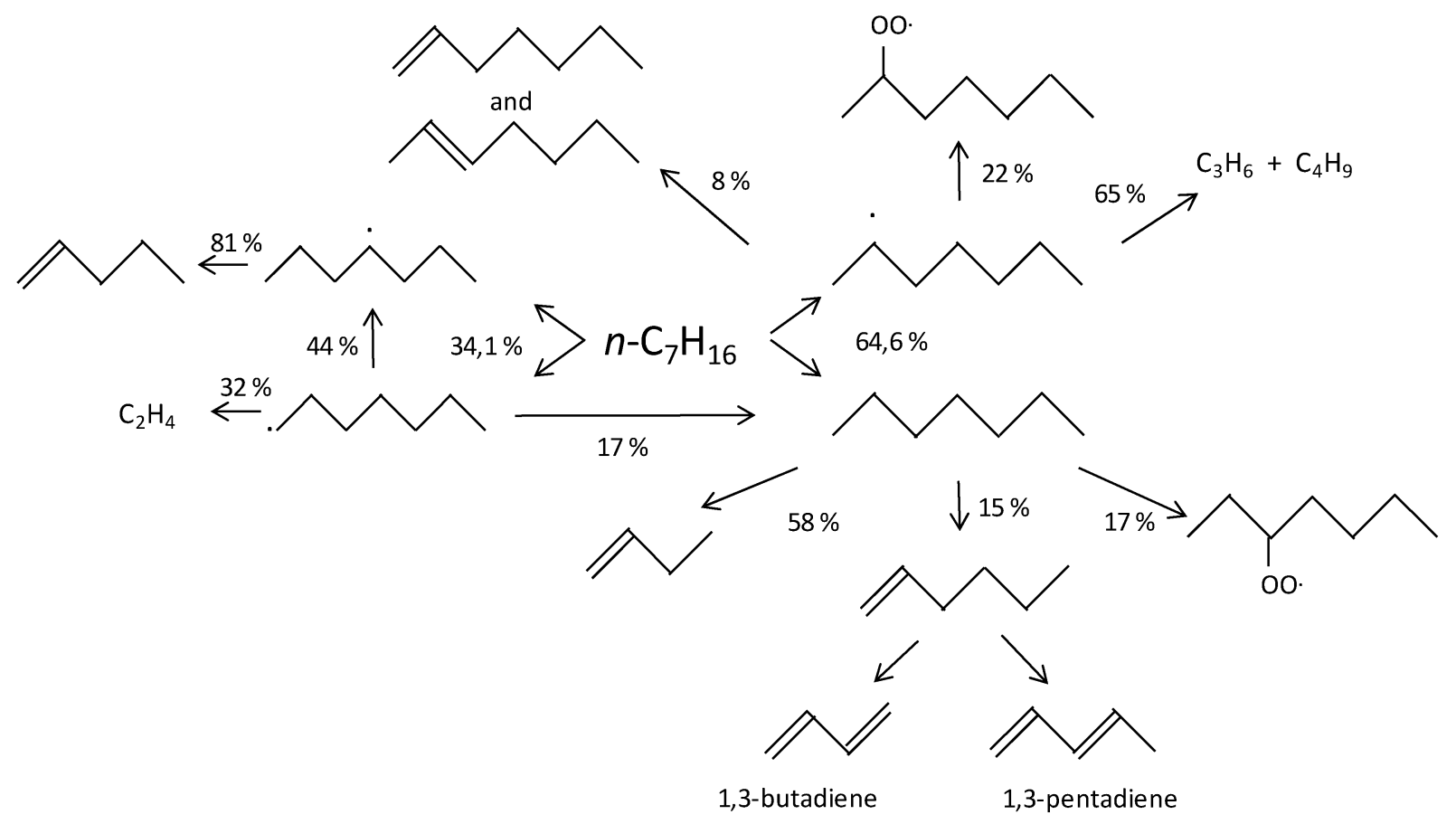

Figure 18.

Rate of production analysis performed at high temperature $(850 \mathrm{~K})$ using the $n$-heptane oxidation model developed in this study. 
Table 1

List of species detected using gas chromatography

\begin{tabular}{|c|c|c|c|}
\hline Name & Global formula & Mass (amu) & $\begin{array}{c}\text { Ionization energy }(\mathrm{eV}) \\
{[48]}\end{array}$ \\
\hline Methane & $\mathrm{CH}_{4}$ & 16 & 12.61 \\
\hline Acetylene & $\mathrm{C}_{2} \mathrm{H}_{2}$ & 26 & 11.40 \\
\hline Carbon monoxide & $\mathrm{CO}$ & \multirow{2}{*}{28} & 14.01 \\
\hline Ethylene & $\mathrm{C}_{2} \mathrm{H}_{4}$ & & 10.51 \\
\hline Ethane & $\mathrm{C}_{2} \mathrm{H}_{6}$ & 30 & 11.52 \\
\hline Propene & $\mathrm{C}_{3} \mathrm{H}_{6}$ & 42 & 9.73 \\
\hline Carbon dioxide & $\mathrm{CO}_{2}$ & \multirow{2}{*}{44} & 13.78 \\
\hline Acetaldehyde & $\mathrm{C}_{2} \mathrm{H}_{4} \mathrm{O}$ & & 10.23 \\
\hline 1,3-butadiene & $\mathrm{C}_{4} \mathrm{H}_{6}$ & 54 & 9.07 \\
\hline 1-butene & $\mathrm{C}_{4} \mathrm{H}_{8}$ & \multirow{2}{*}{56} & 9.55 \\
\hline Acrolein & $\mathrm{C}_{3} \mathrm{H}_{4} \mathrm{O}$ & & 10.11 \\
\hline Propanal & $\mathrm{C}_{3} \mathrm{H}_{6} \mathrm{O}$ & \multirow{2}{*}{58} & 9.96 \\
\hline Acetone & $\mathrm{C}_{3} \mathrm{H}_{6} \mathrm{O}$ & & 9.70 \\
\hline Acetic acid & $\mathrm{C}_{2} \mathrm{H}_{4} \mathrm{O}_{2}$ & 60 & 10.65 \\
\hline 1,3-pentadiene & $\mathrm{C}_{5} \mathrm{H}_{8}$ & 68 & 8.59 \\
\hline 1-pentene & $\mathrm{C}_{5} \mathrm{H}_{10}$ & \multirow{3}{*}{70} & 9.49 \\
\hline Methyl-vinyl-ketone (3-buten-2-one) & $\mathrm{C}_{4} \mathrm{H}_{6} \mathrm{O}$ & & 9.65 \\
\hline 2-butenal & $\mathrm{C}_{4} \mathrm{H}_{6} \mathrm{O}$ & & 9.74 \\
\hline Butanal & $\mathrm{C}_{4} \mathrm{H}_{8} \mathrm{O}$ & \multirow{2}{*}{72} & 9.82 \\
\hline Butanone & $\mathrm{C}_{4} \mathrm{H}_{8} \mathrm{O}$ & & 9.52 \\
\hline Propanoic acid & $\mathrm{C}_{3} \mathrm{H}_{6} \mathrm{O}_{2}$ & 74 & 10.44 \\
\hline 1-hexene & $\mathrm{C}_{6} \mathrm{H}_{12}$ & \multirow{2}{*}{84} & 9.44 \\
\hline 1-penten-3-one & $\mathrm{C}_{5} \mathrm{H}_{8} \mathrm{O}$ & & 9.50 \\
\hline 2-pentanone & $\mathrm{C}_{5} \mathrm{H}_{10} \mathrm{O}$ & \multirow{2}{*}{86} & 9.38 \\
\hline Pentanal & $\mathrm{C}_{5} \mathrm{H}_{10} \mathrm{O}$ & & 9.74 \\
\hline 1,4-heptadiene & $\mathrm{C}_{7} \mathrm{H}_{12}$ & 96 & na \\
\hline 1-heptene & $\mathrm{C}_{7} \mathrm{H}_{14}$ & \multirow{2}{*}{98} & 9.35 \\
\hline 2-heptene & $\mathrm{C}_{7} \mathrm{H}_{14}$ & & 8.84 \\
\hline
\end{tabular}




\begin{tabular}{|c|c|c|c|}
\hline Name & Global formula & Mass (amu) & $\begin{array}{c}\text { Ionization energy }(\mathrm{eV}) \\
{[48]}\end{array}$ \\
\hline 1-hexen-3-one & $\mathrm{C}_{6} \mathrm{H}_{10} \mathrm{O}$ & & na \\
\hline Heptane & $\mathrm{C}_{7} \mathrm{H}_{16}$ & \multirow{3}{*}{100} & 9.93 \\
\hline 2-hexanone & $\mathrm{C}_{6} \mathrm{H}_{12} \mathrm{O}$ & & 9.35 \\
\hline dihydro-5-methyl-2(3H)-furanone & $\mathrm{C}_{5} \mathrm{H}_{8} \mathrm{O}_{2}$ & & na \\
\hline 2-ethyl,5-methyl,furan & $\mathrm{C}_{7} \mathrm{H}_{10} \mathrm{O}$ & 110 & na \\
\hline 2-heptanone & $\mathrm{C}_{7} \mathrm{H}_{14} \mathrm{O}$ & \multirow{8}{*}{114} & 9.3 \\
\hline 3-heptanone & $\mathrm{C}_{7} \mathrm{H}_{14} \mathrm{O}$ & & 9.1 \\
\hline 2-propyl-tetrahydrofuran & $\mathrm{C}_{7} \mathrm{H}_{14} \mathrm{O}$ & & $9.12^{*}$ \\
\hline 2-ethyl,5-methyl-tetrahydrofuran & $\mathrm{C}_{7} \mathrm{H}_{14} \mathrm{O}$ & & $9.05-9.08^{*}$ \\
\hline 2-methyl,4-propyl-oxetane & $\mathrm{C}_{7} \mathrm{H}_{14} \mathrm{O}$ & & na \\
\hline 2,4-diethyl-oxetane & $\mathrm{C}_{7} \mathrm{H}_{14} \mathrm{O}$ & & na \\
\hline 2-ethyl,3-propyl-oxirane & $\mathrm{C}_{7} \mathrm{H}_{14} \mathrm{O}$ & & na \\
\hline 2-butyl,3-methyl-oxirane & $\mathrm{C}_{7} \mathrm{H}_{14} \mathrm{O}$ & & na \\
\hline tetrahydro-5-methyl-2-furanmethanol & $\mathrm{C}_{6} \mathrm{H}_{12} \mathrm{O}_{2}$ & 116 & na \\
\hline 2,4-heptadione & $\mathrm{C}_{7} \mathrm{H}_{12} \mathrm{O}_{2}$ & \multirow{2}{*}{128} & $9.40^{*}$ \\
\hline 3,5-heptadione & $\mathrm{C}_{7} \mathrm{H}_{12} \mathrm{O}_{2}$ & & $9.37^{*}$ \\
\hline
\end{tabular}

The ionization energies of these species were not available in [48] and were calculated in this work (see Table 2) using the composite CBS-QB3 method [49] in Gaussian03 [50]. 
Table 2

Calculated ionization energies $(\mathrm{eV})$ of most expected isomers for $m / z 114$ and 128 deriving from $n$-heptane. Calculations were performed using the composite CBS-QB3 method [49] in Gaussian03 [50].

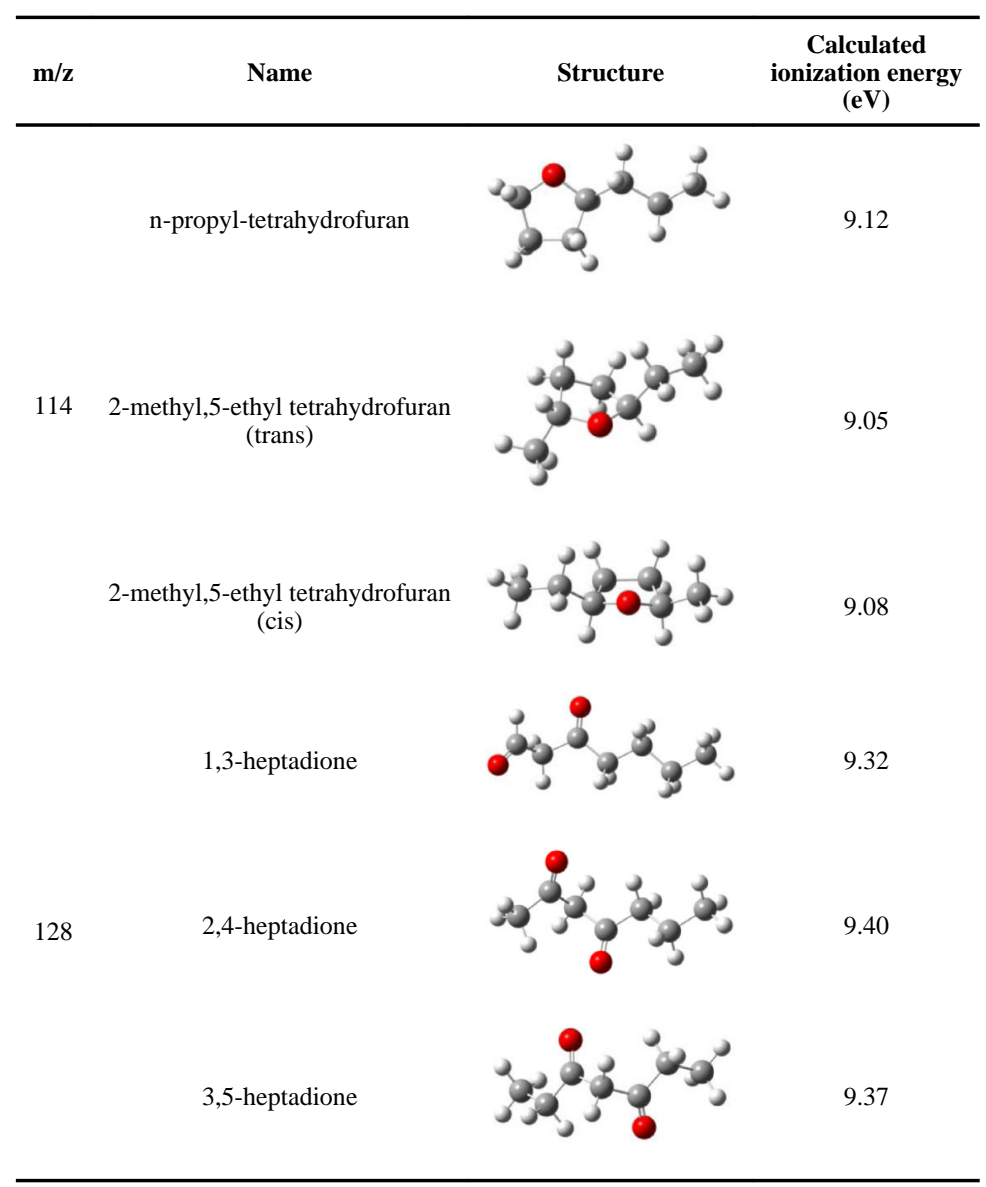




\section{Table 3}

Calculated ionization energies $(\mathrm{eV})$ of some ketohydroperoxide isomers $(\mathrm{m} / \mathrm{zl} 146)$ deriving from $n$-heptane. Calculations were performed using the composite CBS-QB3 method [49] in Gaussian03 [50].

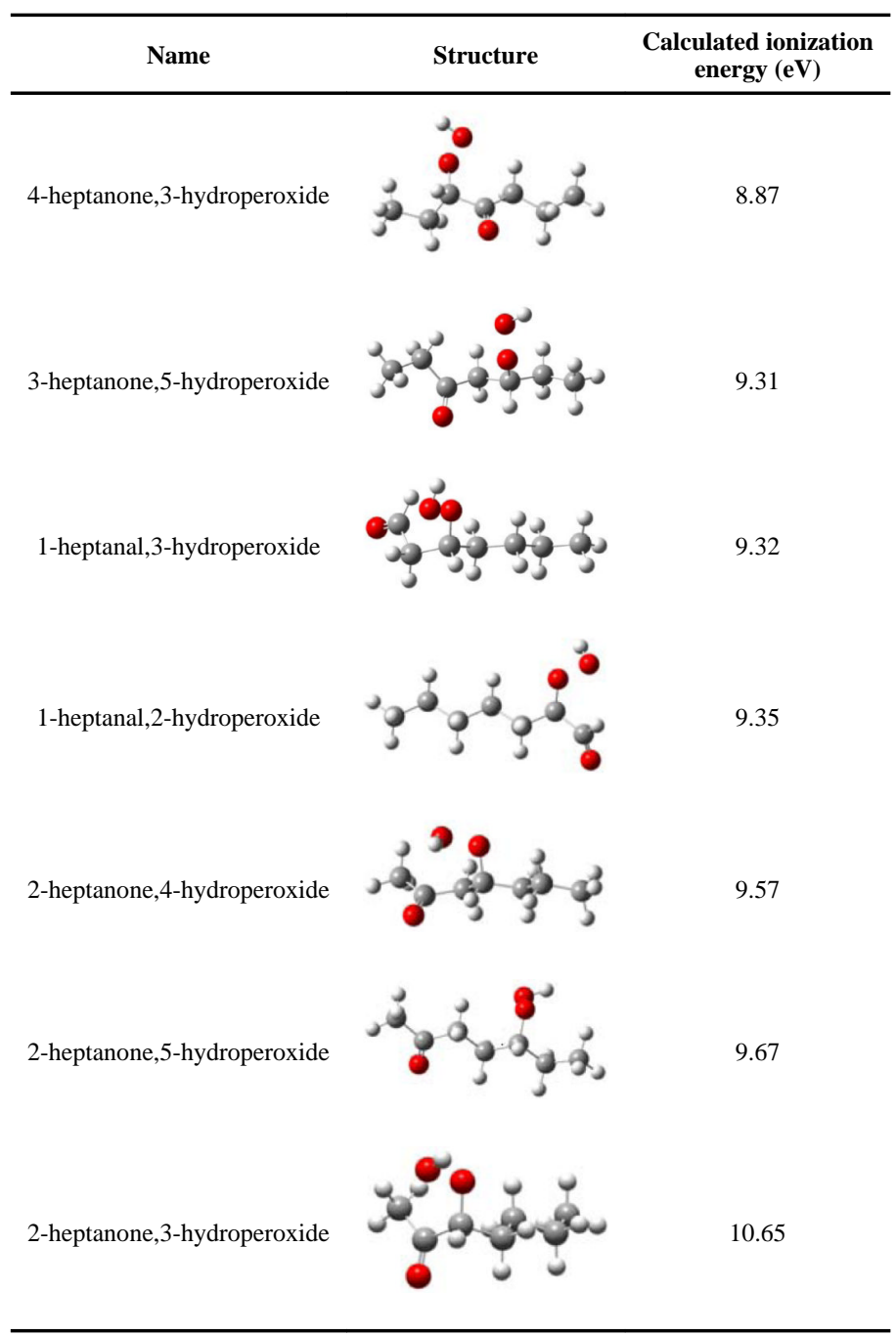




\section{Table 4}

Kinetic parameters of the reactions of consumption of a $\mathrm{C} 5 \mathrm{H} 9 \mathrm{O} 2$ alkoxy radical. Kinetic parameters were obtained performing quantum calculations. Units: cal, mol, $\mathrm{cm}^{3}, \mathrm{~s}$.

\begin{tabular}{cccc}
\hline Reaction in Figure 16 & $\mathbf{A}$ & $\mathbf{n}$ & $\mathbf{E a}\left(\mathbf{c a l}^{. m o l}{ }^{-1}\right)$ \\
\hline$(1)$ & $2.43 \times 10^{9}$ & 1.42 & 19380 \\
$(2)$ & $2.90 \times 10^{12}$ & 0.38 & 11080 \\
$(3)$ & $1.02 \times 10^{12}$ & 0.72 & 15480 \\
$(4)$ & 0.452 & 3.84 & 16850 \\
$(5)$ & 74.92 & 3.49 & 19800 \\
\hline
\end{tabular}

